Article type : Research Article

\title{
DIFFERENTIAL REGULATION OF KIDINS220 ISOFORMS IN
}

\section{HUNTINGTON'S DISEASE}

Álvaro Sebastián-Serrano ${ }^{1,2, *}$, Ana Simón-García ${ }^{1,2}$, Alicia Belmonte-Alfaro ${ }^{1,2}$, Julia Pose-Utrilla ${ }^{1,2}$, María Santos-Galindo ${ }^{2,3}$, Ana del Puerto ${ }^{1,2, \S}$, Lucía García-Guerra ${ }^{1,2}$, Ivó H. Hernández ${ }^{2,3,4}$, Giampietro Schiavo ${ }^{5}$, Miguel R. Campanero ${ }^{1,6}$, José J. Lucas ${ }^{2,3}$ and Teresa Iglesias ${ }^{1,2, *}$.

${ }^{1}$ Instituto de Investigaciones Biomédicas "Alberto Sols". Consejo Superior de Investigaciones Científicas-Universidad Autónoma de Madrid (CSIC-UAM). C/ Arturo Duperier, 4. 28029 Madrid, Spain.

${ }^{2}$ Centro de Investigación Biomédica en Red de Enfermedades Neurodegenerativas (CIBERNED), Instituto de Salud Carlos III, C/ Valderrebollo, 5, 28031 Madrid, Spain.

${ }^{3}$ Centro de Biología Molecular "Severo Ochoa" (CSIC-UAM), C/ Nicolás Cabrera 1, 28049 Madrid, Spain.

${ }^{4}$ Facultad de Ciencias, Departamento de Biología (Unidad Docente Fisiología Animal), Universidad Autónoma de Madrid, Madrid 28049, Spain

${ }^{5}$ Department of Neuromuscular Disorders, UCL Institute of Neurology, University College London, London, WC1N 3BG, UK.

${ }^{6}$ Centro de Investigación Biomédica en Red en Enfermedades Cardiovasculares (CIBERCV), Madrid, Spain.

${ }^{\S}$ Present address: Department of Biotechnology, Instituto Nacional de Investigación y Tecnología Agraria y Alimentaria (INIA), Autovía A6, Km 7,5; Madrid 28040, Spain

This article has been accepted for publication and undergone full peer review but has not been through the copyediting, typesetting, pagination and proofreading process, which may lead to differences between this version and the Version of Record. Please cite this article as doi: 10.1111/bpa.12761

This article is protected by copyright. All rights reserved. 
*Correspondence to:

Álvaro Sebastián-Serrano, Telephone: +34 915854488, E-mail: asserrano@iib.uam.es; and Teresa Iglesias, Telephone: +34 915854487, E-mail: tiglesias@iib.uam.es; Department of Endocrine and Nervous System Physiopathology, Instituto de Investigaciones Biomédicas “Alberto Sols” (CSIC-UAM), C/Arturo Duperier 4, Madrid 28029, Spain.

Running Title: Kidins220-C33 reduction in HD

Keywords: Huntington's disease (HD), Kidins220, excitotoxicity, NMDA, calpain, isoforms.

Abbreviations; days in vitro (DIV); huntingtin (Htt); Huntington's disease (HD); Kinase D-interacting substrate of $220 \mathrm{kDa}$ (Kidins220); Kidins220 N-terminal fragments (Nt-); Kidins220 N-terminal antibody (Kid-Nt); kinesin-interacting motif (KIM); mutant Htt (mHtt); neuronal-specific enolase (NSE); neurotrophins (NT); Nmethyl-D-aspartate (NMDA); NMDA receptor (NMDAR); $75 \mathrm{kDa}$ pan-NT receptor $\left(\mathrm{p} 75^{\mathrm{NTR}}\right)$; tropomyosin receptor kinases (Trks)

\begin{abstract}
Huntington's disease (HD) is an inherited progressive neurodegenerative disease characterized by brain atrophy particularly in the striatum that produces motor impairment, and cognitive and psychiatric disturbances. Multiple pathogenic mechanisms have been proposed including dysfunctions in neurotrophic support and calpain-overactivation, among others. Kinase D-interacting substrate of $220 \mathrm{kDa}$ (Kidins220), also known as ankyrin repeat-rich membrane spanning (ARMS), is an
\end{abstract}


essential mediator of neurotrophin signaling. In adult brain, Kidins 220 presents two main isoforms that differ in their carboxy-terminal length and critical protein-protein interaction domains. These variants are generated through alternative terminal exon splicing of the conventional exon 32 (Kidins220-C32) and the recently identified exon 33 (Kidins220-C33). The lack of domains encoded by exon 32 involved in key neuronal functions, including those controlling neurotrophin pathways, pointed to Kidins220-C33 as a form detrimental for neurons. However, the functional role of Kidins220-C33 in neurodegeneration or other pathologies, including $\mathrm{HD}$, has not been explored. In the present work, we discover an unexpected selective downregulation of Kidins220-C33, in the striatum of HD patients, as well as in the R6/1 HD mouse model starting at early symptomatic stages. These changes are C33-specific since Kidins220-C32 variant remains unchanged. We also find the early decrease in Kidins220-C33 levels takes place in neurons, suggesting an unanticipated neuroprotective role for this isoform. Finally, using ex vivo assays and primary neurons, we demonstrate that Kidins220-C33 is downregulated by mechanisms that depend on the activation of the protease calpain. Altogether, these results strongly suggest that calpain-mediated Kidins220-C33 proteolysis modulates onset and/or progression of HD.

\section{INTRODUCTION}

Huntington's Disease (HD) is a progressive inherited neurodegenerative disorder characterized by motor, cognitive and psychiatric symptoms (32). HD is caused by the autosomal expansion of a CAG repeat within the coding region of the huntingtin $(\mathrm{Htt})$ gene that generates aberrant proteins containing extended polyglutamine stretches (19). Although Htt is an ubiquitously expressed essential protein, cell degeneration in the presence of mutant $\mathrm{Htt}(\mathrm{mHtt})$ occurs mainly in the brain. Early brain damage is more 
evident in the striatum, but atrophy extends to the cortex and other areas as disease progresses $(47,48)$.

The proposed mechanisms for the selective neuronal degeneration observed in this pathology are numerous and complex, including inflammatory processes, excitotoxicity, metabolic impairment, oxidative stress, transcription dysregulation and altered proteolysis (56). Nevertheless, the loss of neurotrophic support induced by $\mathrm{mHtt}$ has been pointed as a major contributor to HD pathology $(54,56)$. The considerable overlap between intracellular signaling networks induced by neurotrophins (NT) and those dysregulated by mHtt (44), together with the neuroprotective role of NT against HDrelated degeneration, provides strong theoretical and experimental support for this notion $(39,40,45,54)$. NTs bind to two types of receptors, denominated tropomyosin receptor kinases (Trks) and $75-\mathrm{kDa}$ pan-NT receptor $\left(\mathrm{p} 75^{\mathrm{NTR}}\right)$, that are classically thought to regulate pro-survival and death signaling, respectively. A majority of studies report that NTs and/or Trks levels decrease while $\mathrm{p} 75^{\mathrm{NTR}}$ content increases in HD brain (4, 17, 30, 45, 54, 55). In accordance, preclinical studies employing small molecule ligands modulating both types of receptors succeed in preventing HD-related pathology, improving cognition and motor abilities $(44,45)$.

A common downstream effector of the neurotrophic pathway in neurons is Kinase D interacting substrate (Kidins220) (22), also known as ankyrin repeat-rich membrane spanning or 'ARMS' (26). Kidins220 is an integral membrane protein (22) essential for neurotrophin signaling that interacts both with Trks and $\mathrm{p} 75^{\mathrm{NTR}}(1,7,26)$. Recent studies have revealed that Kidins 220 shows alternative splicing variants determining the presence or the absence of critical protein-protein interaction domains, which may cause still unexplored structural and functional changes (43). Specifically, in mouse and human adult brain, Kidins220 presents two main isoforms as the result of alternative 
terminal exon splicing from exon 31 to exon 32 or to exon 33 (43). These variants, known as full length and C2 and here respectively named Kidins220-C32 and Kidins220-C33, strongly differ in their carboxy-terminal (C-terminal) length and sequences (see scheme in Figure 1A) (43). In this regard, Kidins220-C33 isoform lacks the kinesin-interacting motif (KIM), the $\mathrm{p} 75^{\mathrm{NTR}}$ binding site and the PDZ-ligand, all domains encoded by exon 32. Both KIM and PDZ-binding motifs are necessary for kinesin-mediated transport and neuronal signal transduction downstream neurotrophic stimulation of Trks $(3,21)$. In turn, exon 33 encodes a short stretch of amino acids whose function and interacting partners are presently unknown. These sharp differences between the C32 and C33 isoforms of Kidins 220 strongly suggest that the physiological functions, molecular partners and subcellular location(s) of the later variant might markedly differ from those assigned to Kidins220-C32 (35). Furthermore, human Cterminal missense mutations causing a new syndrome with spastic paraplegia, intellectual disability, nystagmus, and obesity (SINO) $(24,53)$ generate truncated forms of Kidins220-C32 resembling Kidins220-C33. This truncated Kidins220 protein might cause detrimental outcomes for fundamental neuronal functions and survival such as those involved in NT-signaling. Together, these data suggest that Kidins220-C33 isoform may play opposite effects to those of Kidins220-C32 and therefore be detrimental to neuronal function and survival.

Excitotoxicity is a form of neuronal death triggered by overactivation of N-methyl-Daspartate (NMDA) receptors (NMDARs) by high concentrations of its agonist glutamate. Our group recently demonstrated that excitotoxicity, induced by a model of cerebral ischemia or in cultured cortical neurons, produces a sharp decrease in the levels of Kidins220-C32 (29). Excitotoxic downregulation of Kidins220-C32 directly contributes to neuronal death and is triggered by high $\mathrm{Ca}^{2+}$ influx through NMDARs 
involving a massive and rapid cleavage of the protein by the $\mathrm{Ca}^{2+}$-dependent protease calpain (16, 29). Kidins220-C32 C-terminal region is extraordinarily sensitive to activated calpain and contains a great number of cleavage sites for this protease (16, 29). Importantly, prevention of excitotoxic-driven proteolysis of Kidins220-C32 confers neuroprotection $(16,29)$, again suggesting that truncated forms of this variant may be associated to neuronal death.

NMDAR-mediated excitotoxicity and calpain overactivation play a critical role in the pathogenesis of $\operatorname{HD}(8,9,13,14,18,25,38,50)$. Accordingly, preclinical studies in HD animal models have proven the beneficial effect of directly or indirectly lowering calpain activity $(8,33,50)$.

Kidins220-C32 sensitivity to calpain action varies depending on the neurodegeneration context. Acute neurodegeneration provoked by an ischemic episode results in a rapid and strong calpain-dependent downregulation of Kidins220-C32 (16, 29). By contrast, this protein shows higher resistance to calpain cleavage and accumulates in Alzheimer's disease $(\mathrm{AD})$ brain and cerebrospinal fluid $(15,28)$. Along the same line, a very recent publication describes augmented Kidins220-C32 levels in hippocampal and cortical necropsies of HD patients as well as in the hippocampus of HD mouse models (27), even though this accumulation has not been related to calpain resistance. Besides these data, there are no available studies analyzing Kidins 220 levels in striatum, the most vulnerable brain region in HD. In addition, potential dysregulation of Kidins 220 isoforms in pathology, including neurodegenerative diseases, has not been explored.

Here we have investigated the dynamics of Kidins220-C32 and C33 isoforms in HD striatum as well as in other brain areas. Strikingly, we have found an unexpected and highly significant decrease of Kidins220-C33 isoform expression in striatal necropsies of $\mathrm{HD}$ patients. Brain samples from the R6/1 mouse model show a similar drop of 
Kidins220-C33 levels, both at early and late symptomatic stages, that is not paralleled by changes in Kidins220-C32 levels. We have also examined the potential causes of these alterations and discuss functional implications.

\section{MATERIALS AND METHODS}

\section{Human brain tissue samples}

Human samples came from the Neurological Tissue Bank of the IDIBAPS Biobank (Barcelona, Spain), the Banco de Tejidos Fundación Cien (BT-CIEN, Madrid, Spain) and the Netherlands Brain Bank (Amsterdam, The Netherlands). Written informed consent for brain removal after death for diagnostic and research purposes was obtained from brain donors and/or next of kin. Procedures, information and consent forms were approved by the Bioethics Subcommittee of Centro Superior de Investigaciones Científicas (Madrid, Spain). When available, the gender, the neuropathological examination of HD cases to assign HD grade from 0-1 to 4 following Vonsattel's criteria, and the number of CAG repeats are shown in Table 1. The post-mortem interval in tissue processing was between 4:00 and 17:00 h (Table 1).

\section{Animals}

R6/1 transgenic mice for the human exon-1-HTT gene (31) in B6CBAF1 background were housed at the Centro de Biología Molecular "Severo Ochoa" (CBMSO, CSICUAM, Madrid, Spain) animal facility. Wistar rat embryos of 19 days were obtained from the animal care facility at the Instituto de Investigaciones Biomédicas “Alberto Sols“ (IIBm, CSIC-UAM, Madrid, Spain). All animals were housed maximum four per cage with food and water available ad libitum and maintained in a temperature controlled environment on a 12/12 h light-dark cycle with light onset at 07:00 h. 
Animal housing and maintenance protocols followed the guidelines of Council of Europe Convention ETS123, recently revised as indicated in the Directive 86/609/EEC. Animal experiments were performed under protocols approved by institutional (IIBm, CBMSO and CSIC) and local Ethical Committees and were conformed to the appropriate national legislations (RD 53/2013).

\section{Primary culture and treatment of cortical neurons}

Rat cortical neurons were prepared from cerebral cortex of 19-day-old Wistar rat embryos. After removal of meninges, cerebral cortices were mechanically dissociated in $4 \mathrm{ml}$ of minimum essential medium (MEM) completed with penicillin (100 U/ml), streptomycin $(100 \mathrm{U} / \mathrm{ml}), 22.2 \mathrm{mM}$ glucose, Glutamax-I, $5 \%$ fetal bovine serum (FBS) and $5 \%$ horse serum (HS), all these reagents from Thermo Fisher Scientific (Rockford, IL, USA). Then, extracts were centrifuged at $1000 \mathrm{~g}$ for $5 \mathrm{~min}$, cellular pellets were resuspended and plated at a density of $0.22 \times 10^{6} \mathrm{cells} / \mathrm{cm}^{2}$, in plates covered with polyL-lysine $(10 \mu \mathrm{g} / \mathrm{ml})$ and laminin $(4 \mu \mathrm{g} / \mathrm{ml})$ (both from Sigma-Aldrich, St. Louis, MO, USA).

Cells were incubated at $37^{\circ} \mathrm{C}, 5 \% \mathrm{CO}_{2}$ and $95 \%$ humidity. Neurons were used after 14 days in vitro (DIV). Neurons were treated for different time periods with: $100 \mu \mathrm{M}$ NMDA (Sigma- Aldrich), $10 \mu \mathrm{M}$ glycine (Sigma-Aldrich), $20 \mu \mathrm{M}$ calpain inhibitor (CiIII; Calbiochem-Merck Bioscience, Darmstadt, Germany), $200 \mu \mathrm{M}$ DL-2-amino-5phosphonopentanoic acid (DL-AP5; Tocris Bioscience, Bristol, UK) or 2 mM EGTA (Sigma-Aldrich). Excitotoxicity was induced in cortical neurons by overstimulation of NMDAR with the co-agonists NMDA and glycine at the concentrations indicated above. Inhibitors were added $1 \mathrm{~h}$ before NMDA-treatment and remained in the culture media for the duration of the experiment. 


\section{Antibodies}

Rabbit polyclonal Kidins220-C32 (recognizing both human and mouse), 1:2000 for immunoblot and 1:500 for immunohistochemistry, purified from an antiserum, generated as described (22), using as immunogen a 17 aminoacid-peptide from Cterminus of the protein; Two different rabbit monoclonal antibodies for Kidins220-C33 (recognizing only human or only mouse), 1:200 for immunoblot and 1:500 for immunohistochemistry, were raised by BioGenes using purified GST-exon 33 fusion proteins corresponding to human or mouse (43); rabbit polyclonal antibody recognizing N-terminal region of Kidins220 (Kid-Nt), 1:500 has been previously described (6); antirabbit neuronal specific enolase (NSE), 1:10,000 (ICN Biomedicals, Costa Mesa, CA, USA); anti-mouse $\beta$-actin, 1:10,000; and anti-mouse spectrin, 1:5,000 (Sigma-Aldrich); anti-mouse Htt, 1:1,000; and anti-mouse NeuN, 1:500 (Merck Millipore, Billerica, MA, USA); horseradish peroxidase-conjugated anti-rabbit, 1:5,000; and anti-mouse, 1:2,000 secondary antibodies (Santa Cruz Biotechnology, CA, USA); fluorescent secondary antibodies donkey anti-rabbit, 1:500; and anti-mouse, 1:500 conjugated with AlexaFluor 488, 546 or 647 (Thermo Fisher Scientific).

\section{Preparation of protein extracts and immunoblot analysis}

Samples from human brain were stored at $-80^{\circ} \mathrm{C}$ and ground with a mortar using liquid nitrogen to prevent thawing of the samples. Mouse brains were quickly dissected on an ice-cold plate and the different structures stored at $-80{ }^{\circ} \mathrm{C}$. Extracts from human brain cortex were prepared in $1 \%$ SDS in PBS, $5 \mathrm{mM}$ EDTA and $5 \mathrm{mM}$ EGTA, containing protease and phosphatase inhibitors. Homogenization of the samples was performed with a POLYTRON System PT 1200 E (Kinematica AG, Lucerne, Switzerland) and lysates were then centrifuged at $21,000 \mathrm{~g}$ for $30 \mathrm{~min}$ at $4^{\circ} \mathrm{C}$.

This article is protected by copyright. All rights reserved. 
Mouse protein extracts were prepared by homogenizing samples in ice-cold extraction buffer [20 mM HEPES pH 7.4, $100 \mathrm{mM} \mathrm{NaCl,} 20 \mathrm{mM} \mathrm{NaF}, 1 \%$ Triton X-100, $1 \mathrm{mM}$ sodium orthovanadate, $1 \mu \mathrm{M}$ okadaic acid, $5 \mathrm{mM}$ sodium pyrophosphate, $30 \mathrm{mM} \beta$ glycerophosphate, $5 \mathrm{mM}$ EDTA, protease inhibitors (Complete, Roche, Cat. No 11697498001)]. Homogenates were centrifuged at $15,000 \mathrm{rpm}$ for $15 \mathrm{~min}$ at $4{ }^{\circ} \mathrm{C}$.

To obtain protein extracts from primary cultures cellular lysis was performed using RIPA buffer (25 mM Tris-HCl, $\mathrm{pH} 7.6,1 \%$ Triton $\mathrm{X}-100,0.5 \%$ sodium deoxycholate, $0.1 \% \mathrm{SDS}, 150 \mathrm{mM} \mathrm{NaCl}$ and $1 \mathrm{mM}$ DTT) with protease and phosphatase inhibitors (1 $\mathrm{mM}$ phenylmethylsulfonyl fluoride, $10 \mu \mathrm{g} / \mathrm{ml}$ aprotinin, $10 \mu \mathrm{g} / \mathrm{ml}$ leupeptin, $50 \mathrm{mM}$ sodium fluoride, $5 \mathrm{mM}$ sodium pyrophosphate and $1 \mathrm{mM}$ sodium metavanadate, all from Sigma-Aldrich) added to the cultures, maintained in agitation for $30 \mathrm{~min}$ at $4^{\circ} \mathrm{C}$ and subsequent centrifugation at $21,900 x \mathrm{~g}$ for $30 \mathrm{~min}$ at $4^{\circ} \mathrm{C}$. Protein content in all extracts was determined by BCA assay (Thermo Fisher Scientific).

Separation of the proteins was performed on $8 \%$ SDS-PAGE gels. Proteins were transferred to nitrocellulose membranes, blocked for $30 \mathrm{~min}$ at room temperature (RT) with $5 \%$ nonfat dried milk in tween-Tris-buffered saline $(137 \mathrm{mM} \mathrm{NaCl}, 20 \mathrm{mM}$ Tris$\mathrm{HCl} \mathrm{pH} 7.6,0.05 \%$ Tween-20) (TBS-T) and incubated overnight at $4^{\circ} \mathrm{C}$ with primary antibodies. Blots were then washed in TBS-T, and incubated for $1 \mathrm{~h}$ at RT with horseradish peroxidase-conjugated anti-rabbit $(1: 5,000)$ or anti-mouse $(1: 2,000)$ secondary antibodies (Santa Cruz Biotechnology). Protein bands were detected by ECL chemiluminescence (Perkin-Elmer Life Sciences, Boston, MA, USA). Immunoblot signals were quantified by densitometric analysis (NIH ImageJ, Bethesda, MD, USA), normalized using $\beta$-actin or NSE, and expressed relative to values obtained in their respective controls. In the figures, representative Western blot images show only the quantified bands.

This article is protected by copyright. All rights reserved. 


\section{Quantitative reverse transcription-PCR (RT-qPCR)}

Total tissue RNA was extracted from striatum and cortex of HD and control subjects and from striatum of R6/1 and WT mice using the Maxwell® 16 LEV simplyRNA Tissue Kit (Promega, Madison, WI, USA). The resulting total RNA (750 ng) was used for cDNA synthesis with a Super Script III First-Strand Synthesis SuperMix kit from Invitrogene (PN 11752250) with the amplification protocol $30^{\prime \prime}$ at $95^{\circ} \mathrm{C}+\left(5^{\prime \prime}\right.$ at $95^{\circ} \mathrm{C}+$ $5^{\prime \prime}$ at $\left.60^{\circ} \mathrm{C}\right) \times 40+\left(5^{\prime \prime}\right.$ at $60^{\circ} \mathrm{C}+5^{\prime \prime}$ at $\left.95^{\circ} \mathrm{C}\right)$. Quantification was performed by real-time PCR using a CFX 384 System (Bio-Rad) in combination with SsoFast Eva Green (BioRad, Hercules, CA, USA), as per manufacturer's protocol and $1 \mu 1$ of primer pair was used. Data were analyzed by GenEx 5.3.7 software (Multid AnaLyses AB). The mRNA levels were normalized first relative to total RNA and then relative to the mean of GADPH, $\beta$-actin and $\beta$-tubulin gene expression for human and the mean of $18 \mathrm{~S}$ ribosome subunit, GADPH, $\beta$-actin and $\beta$-tubulin gene expression for mouse in each sample. mRNA abundance was calculated using the $2^{-\Delta \Delta C t}$ method and assigned arbitrarily 1 value to one control sample. The primers used are indicated in Table 2 .

\section{Tissue preparation, immunofluorescence and immunohistochemistry.}

Mice euthanasia was performed using $\mathrm{CO}_{2}$. Brains were immediately removed and dissected on an ice-cold plate and left hemispheres, processed for histology, placed in 4\% paraformaldehyde in Sorensen's phosphate buffer overnight and then immersed in $30 \%$ sucrose in PBS for $72 \mathrm{~h}$. Once cryoprotected, samples were included in optimum cutting temperature compound (OCT; Tissue-Tek, Sakura Finetek Europe), frozen and stored at $-80{ }^{\circ} \mathrm{C}$ before use. $30 \mu \mathrm{m}$ sagittal sections were cut on a cryostat (Thermo Fisher Scientific), collected and stored free floating in glycol containing buffer $(30 \%$ glycerol, $30 \%$ ethylene glycol in $0.02 \mathrm{M}$ phosphate buffer) at $-20{ }^{\circ} \mathrm{C}$. For 
immunofluorescence analysis floating parasagittal sections were incubated in blocking solution (1\% BSA, $1 \%$ Triton $\mathrm{X}-100$ in $0.1 \mathrm{M}$ PBS) with primary antibodies overnight at $4{ }^{\circ} \mathrm{C}$ and subsequently incubated $2 \mathrm{~h}$ at $4{ }^{\circ} \mathrm{C}$ with fluorescent-labeled secondary antibodies. Then, slices were rinsed in PBS and nuclei were stained with DAPI and mounted with Fluoromount $G^{\circledR}$ (SouthernBiotech, Birmingham, AL, USA).

For immunohistochemistry analysis parasagittal brain sections from 7.5-month-old WT and R6/1 mice corresponding to late symptomatic state were stained free-floating. Endogenous peroxidase was inactivated by incubating sections in a solution of $0.3 \%$ hydrogen peroxide in PBS for 45 min. Brain sections were pretreated for $1 \mathrm{~h}$ with blocking solution consisting in 1\% BSA, 5\% FBS, and 0.1\% Triton X-100 in PBS, and subsequently incubated over-night with rabbit polyclonal antibodies against Kidins 220 murine isoforms in blocking solution. After washing primary antibody with PBS, sections were incubated with anti-rabbit secondary antibody conjugated with biotin for $2 \mathrm{~h}$. Finally, chromogenic signal was amplified by incubating sections for $1.5 \mathrm{~h}$ with avidin-biotin complex using Elite Vectastain kit (Vector Laboratories, Burligame, CA, USA). Chromogen 3-3' diaminobenzidine (DAB) reactions were performed as manufacturer's protocol with Sigma-FAST for 10 min before mounting with mowiol.

For cultured neurons, primary neurons grown on coverslips were fixed with $4 \%$ PFA with $4 \%$ sucrose, permeabilized with $0.1 \%$ Triton X-100 in PBS for 5 min and then incubated in 4\% BSA in PBS for 30 min. Coverslips were then incubated for $1 \mathrm{~h}$ at RT with the appropriate primary antibody in blocking solution followed by the corresponding secondary antibody. The nuclei were stained with DAPI and coverslips were mounted with Fluoromount $\mathrm{G}^{\circledR}$ (SouthernBiotech).

This article is protected by copyright. All rights reserved. 


\section{Quantitative and statistical analysis}

Cellular localization of Kidins220 isoforms by immunofluorescence and confocal microscopy in WT brain slices was analyzed by counting the presence or absence of the corresponding protein in 120-210 neurons (NeuN+ cells) or 60-75 astrocytes (GFAP+ cells) per mouse. Chromogen intensity was quantified using the reciprocal intensity (r) method (37), where: $r=255-y, 255$ being the maximum pixel intensity of unstained area (as measured by the mean gray value in the Image J software) and $y=$ mean intensity of the region of interest (ROI) randomly selected in the cerebral cortex. Reciprocal intensity was quantified from five ROIs per field of three mice per group. For each field, the background measured in a free-cell zone was subtracted. For the analysis of immunofluorescence signal of Kidins220-C33 in NeuN+ cells in WT and R6/1 mice, the intensity of Kidins220-C33 staining was measured in 600-800 NeuN+ neurons per animal and compared to the value of the mean obtained from WT animals.

Statistical analysis was performed with GraphPad Prism (version 5.00 for Windows, GraphPad Software, San Diego, CA, USA, www.graphpad.com). Data are represented as mean \pm s.e.m. derived from the indicated number of patients or non-affected individuals, mice or experiments. For two-group comparison, data were analyzed with two-tailed unpaired Student's t-test, and for multiple comparisons, with One-way ANOVA and Bonferroni post-hoc test. A critical value for significance of $* P<0.05$, $* * P<0.01$ or $* * * P<0.001$ was used throughout the study.

This article is protected by copyright. All rights reserved. 


\section{RESULTS}

\section{Decreased levels of Kidins220-C33 isoform in human HD striatum necropsies}

To study how HD pathology might influence Kidins220 expression, we analyzed protein levels of Kidins220-C32 and Kidins220-C33 (43) in necropsies from striatum and cortex of HD patients and control individuals (see Table 1 for details). We performed immunoblot analysis of human brain lysates using antibodies specific to Kidins220-C32 or to Kidins220-C33 (Figure 1A). Human, rat and mouse Kidins220C32 share identical C-terminal ends, thus the specific antibody initially generated (22) and used in multiple reports $(5,16,20,28,29)$ detects this isoform in these species. Exon 33 encodes however different amino acid sequences in human and mouse and two specific antibodies were used (see scheme in Supplementary Figure 1A). We therefore pre-absorbed human specific Kidins220-C33 antibody with the immunizing peptide to confirm the specificity of this antibody with human samples (Supplementary Figure 1B). Analysis of Kidins220-C33 expression revealed that it was markedly diminished in striatum of HD patients (Figure 1B). In contrast, Kidins220-C32 protein levels remained unchanged (Figure 1B). Furthermore, regression analysis of relative expression of both isoforms showed no correlation between Kidins220-C32 and C33 expression in healthy control brains (Supplementary Figure 2). To investigate if the cause of decreased levels of Kidins220-C33 was related with an altered transcriptional mechanism, we analyzed mRNA levels in the striatum and cortex of HD patients and controls by qRT-PCR. We found no differences in Kidins220-C33 mRNA, but surprisingly cortical KIDINS220C32 transcripts presented slightly but significantly increased levels in HD compared to control samples (Figure 1C). Altogether, these results demonstrate that Kidins220-C33 protein levels are decreased in the striatum of HD patients, most likely by posttranscriptional mechanisms.

This article is protected by copyright. All rights reserved. 


\section{Early loss of Kidins220-C33 splice variant in R6/1 brain.}

Next, we examined whether the R6/1 mouse model of HD displayed similar changes in Kidins220-C32 and Kidins220-C33. Protein levels were analyzed by immunoblot, after confirming the specificity of the antibody recognizing murine Kidins220-C33 in mouse samples (Supplementary Figure 1C). To assess protein expression during disease progression, we used 3.5- and 7.5-month-old R6/1 mice corresponding to early symptomatic and late stage of disease, respectively (10). We found substantially decreased levels of Kidins220-C33 protein in striatum and cerebral cortex at both stages while the hippocampus only showed decreased Kidins220-C33 expression at late stage of disease (Figure 2A and 2B). Specifically, a reduction to $57.4 \pm 9.9 \%(\mathrm{p}<0.05)$ in the striatum and $79.9 \pm 3.9 \%(\mathrm{p}<0.05)$ in the cerebral cortex of 3.5 -month-old R6/1 compared to wild-type (WT) mice was found (Figure 2A). In contrast, Kidins220-C32 levels were not decreased in any of these brain areas (Figure 2A and 2B). This decrease in Kidins220-C33 protein levels in the striatum of R6/1 mice does not seem to be due to altered transcription of the gene because qRT-PCR analysis of RNA extracted from the striatum of 7.5-month-old R6/1 mice revealed no significant differences compared to control (Figure 2C). In contrast, and similarly to what was observed in human cortical samples, striatal Kidins220-C32 transcripts showed a significant increase of nearly $60 \%$ $(\mathrm{p}<0.01)$ (Figure 2C). Collectively, these results indicate that Kidins220-C32 and Kidins220-C33 isoforms are differentially regulated in HD human samples and in the R6/1 HD mouse model.

This article is protected by copyright. All rights reserved. 


\section{Kidins220-C33 downregulation occurs mainly in neurons}

To identify which cells express these two Kidins 220 isoforms, we double stained brain sections from WT mice with antibodies against Kidins220-C32 or Kidins220-C33 and neuron (NeuN) or astrocyte (GFAP) specific markers. Immunofluorescence and confocal microscopy analysis showed that while Kidins220-C32 was present in a big proportion of neurons and astrocytes, Kidins220-C33 staining was mainly neuronal (Figure $3 \mathrm{~A}$ and $3 \mathrm{~B}$ ). In order to analyze and quantify the decrease of Kidins220-C33 levels in intact R6/1 brain slices we first used immunohistochemistry. As shown in Figure 3C and 3D, we detected a strong loss of Kidins220-C33 staining in the cortex of R6/1 mice compared to WT animals while Kidins220-C32 signal remained unaltered. Unfortunately, Kidins220-C33 staining in WT or R6/1 striatum was undetectable. We further confirmed Kidins220-C33 decline occurred in neurons in early symptomatic R6/1 mice cortex, by performing a double immunofluorescence and quantifying the signal of this isoform in NeuN+ cells by confocal microscopy analysis (Figure 3E and 3F). Together, our data strongly suggest that the decrease of Kidins220-C33 levels observed by immunoblotting is due to loss of neuronal expression at early stages of the disease.

Previous work by our group demonstrated that Kidins220-C32 was aggregated around senile plaques of $\beta$-amyloid in brain necropsies from $\mathrm{AD}$ patients (28). Considering that mHtt toxic products accumulate and form inclusion bodies in HD (11), we investigated whether Kidins220 variants aggregated with mHtt. Double Kidins220 isoforms and mHtt immunofluorescence analysis of brain slices from 7.5-month-old R6/1 mice showed no colocalization of Kidins220-C32 or Kidins220-C33 with mHtt aggregates (Figure 3G). These results indicate that Kidins220 variants are not sequestered in neuronal HD inclusion bodies.

This article is protected by copyright. All rights reserved. 


\section{Kidins220-C33 is expressed in rat neurons}

Next, we aimed to confirm that Kidins220-C33 is expressed in primary cultures of rat cortical neurons, an in vitro model frequently used for our studies (28). Since Kidins220-C33 variant has not been previously identified in the rat, we carried out an in silico analysis of the rat genome, searching for homologies with the mouse orthologue (43). BLAST alignment revealed that rat and mouse genome exon 33 sequences were highly similar, differing only in two nucleotides (Figure 4A). This sequence was located 3416 base pairs upstream from the 3' end of the rat Kidins220 gene, in chromosome 6 (Supplementary Figure 3). In addition, rat and mouse sequences encoded an identical peptide (Figure 4A) and the antibody employed to detect murine Kidins220-C33 also recognized this isoform in rat striatum, hippocampus, cerebellum and cortex in immunoblotting (Figure 4B). Finally, immunofluorescence of cultured rat cortical neurons detected Kidins220-C33 neuronal expression following a similar pattern to that observed in mouse brain slices (Figure 4C, see also Figure 3E to compare). Altogether, these results demonstrate the presence of Kidins220-C33 in the rat genome and its neuronal localization in cultured rat neurons.

\section{Increased susceptibility of Kidins220-C33 isoform to protease processing}

Kidins220-C32 downregulation by excitotoxicity is mediated by calpain-dependent proteolysis (28). Since excitotoxicity and calpain overactivation play key roles in HD pathogenesis (18), we hypothesized that the observed decrease in Kidins220-C33 levels in R6/1 mice and HD patients could be due to calpain-dependent mechanisms. To test this hypothesis, and considering that calpain is involved in post-mortem proteolysis (46), we analyzed Kidins220-C33 protein levels by immunoblotting in extracts prepared from WT mice brain harvested at different post-mortem intervals (0-24 h). As a control, 
we determined Kidins220-C32 levels in the same samples, since we demonstrated that spontaneous post-mortem calpain activation provokes extensive processing in human and mouse brain (28). Full-length (FL) spectrin and its break-down products (BDPs) derived from calpain mediated proteolysis were monitored as a control of the activity of this protease on a canonical substrate (Figure 5A).

As expected, Kidins220-C32 presented a linear decrease of its levels as time postmortem increased, reaching statistical significance at $6 \mathrm{~h}$ post-mortem. Interestingly, Kidins220-C33 appeared to be more sensitive to calpain-dependent processing, displaying faster kinetics of downregulation with an earlier significant difference after 4 $\mathrm{h}$ (Figure 5A and 5B). These data indicate that both Kidins220-C32 and Kidins220-C33 are proteolyzed and suggest that the latter was more susceptible to proteolytic processing.

To deepen into Kidins220-C33 processing and the generation of potentially derived fragments, we used an antibody recognizing Kidins220 N-terminal region (Kid-Nt; see scheme in Supplementary Figure 4A). In previous reports we demonstrated that Kid-Nt is able to identify N-terminal fragments (Nt-) generated by Kidins220-C32 calpain cleavage under excitotoxic conditions $(15,16)$. Kidins220-C32 and Kidins220-C33 share identical N-terminal sequences (Supplementary Figure 4A) and thus this antibody should identify both full-length isoforms and their putative derived isoform-specific processing products. Here, we initially checked Kid-Nt antibody in mouse brain homogenates collected at different times post-mortem $(\mathrm{t}=0-24 \mathrm{~h})$ (Figure $5 \mathrm{~A})$. After 24 $\mathrm{h}$ there was a significant increase of Kidins220 Nt-5/6 (109-115 kDa) and Nt-7/8 (80-85 $\mathrm{kDa}$ ) fragments that correlated with augmented spectrin BDPs (Figure 5A and 5C). To examine whether Kid-Nt could specifically identify bands corresponding to Kidins220$\mathrm{C} 33$, a duplicate of time 0 was loaded in parallel, cut vertically after transferring and 
incubated with specific mouse C33 C-terminal antibody to detect the corresponding band and compare it to that obtained with Kid-Nt antibody (Supplementary Figure 4B). It can be seen that $\mathrm{C} 33$ band and Nt-5/6 fragment migrate with highly similar molecular weight, hampering the identification of a signal that could be assigned specifically to full-length Kidins220-C33. Altogether these results suggest that Kidins220-C33 cannot be unequivocally and specifically detected by Kid-Nt antibody, and also that Nt-7/8 calpain-derived fragments from Kidins220-C32 and Kidins220-C33 are equally undistinguishable.

\section{Increased spectrin BDPs and Kidins220 Nt-fragments in HD brain}

To analyze whether calpain accounted for Kidins220-C33 decrease in HD and R6/1 brain, we first focused on the appearance of spectrin BDPs as a control of the activity of this protease. Immunoblot analysis of human brain samples revealed that BDPs were markedly augmented in striatum and cortex of HD patients (Figure 6A). Striatum lysates from early symptomatic R6/1 mice also displayed increases in spectrin BDPs (Figure 6B). Furthermore, analysis of samples from late symptomatic R6/1 animals using Kid-Nt antibody revealed raises in a band with similar molecular weight to that of Nt-7/8 fragments in striatum and cortex compared to WT mice (Figure 6C). By contrast, we were unable to detect any additional band that could correspond to C-terminal fragments using Kidins220-C33 C-terminal specific antibody (Supplementary Figure 4C), similarly to what we reported to occur with Kidins220-C32 C-terminal antibody in the recognition of C-terminal processing products (16). Considering that full-length Kidins220-C33 levels decrease in R6/1 brain samples, while Kidins220-C32 levels remain unchanged, our data suggest Nt fragments may originate from Kidins220-C33 
calpain proteolysis. Altogether these results support increased proteolytic cleavage of Kidins220 and overactivation of calpain in HD brain.

\section{Downregulation of Kidins220-C33 in excitotoxicity by calpain-related processing}

To gain insight on the possible calpain-dependent downregulation of Kidins220-C33, we used an excitotoxicity model based on NMDARs overactivation in rat cortical neurons to demonstrate Kidins220-C32 calpain-mediated proteolysis (28). We examined Kidins 220 isoforms in lysates from neurons incubated with $100 \mu \mathrm{M}$ NMDA and the co-agonist glycine $(10 \mu \mathrm{M})$ (hereinafter referred to as "NMDA") for different times. These conditions overstimulate NMDARs and provoke excitotoxicity.

In accordance to previous results (29), immunoblot analysis showed that $2 \mathrm{~h}$ of treatment with NMDA decreased Kidins220-C32 to levels of $45.0 \pm 9.2 \%(\mathrm{p}<0.05)$ relative to untreated cells; stimulation over $6 \mathrm{~h}$ further reduced Kidins220-C32 levels to $26.9 \pm 5.5 \%(\mathrm{p}<0.01)($ Figure 7A). Importantly, Kidins220-C33 underwent an even greater degradation with values of $37.7 \pm 7.5 \%(\mathrm{p}<0.001)$ and $20.1 \pm 5.6 \%(\mathrm{p}<0.001)$ relative to control, 2 or $6 \mathrm{~h}$ after NMDA addition, respectively (Figure 7A). Decreases in Kidins220 isoforms were paralleled by increases in spectrin BDPs (Figure 7A, right panel). Neuronal-specific enolase (NSE) levels were not substantially modified after NMDA treatment (Figure 7A), suggesting that Kidins220 isoforms decrease was not a consequence of a massive neuronal death.

Next, we examined whether Kidins220-C33 downregulation relied on excitotoxic stimulation of NMDARs, $\mathrm{Ca}^{2+}$ entry and calpain proteolysis (29). Pre-treatment of neurons for $1 \mathrm{~h}$ with the generic NMDAR antagonist DL-AP5 $(200 \mu \mathrm{M})$, completely prevented the decrease in Kidins220-C33 and Kidins-C32 evoked by 4 h NMDA treatment (Figure 7B). In the same way, extracellular $\mathrm{Ca}^{2+}$ buffering with $2 \mathrm{mM}$ EGTA 
hampered NMDA-induced degradation of both variants (Figure 7C). Finally, inhibition of calpain activity by $1 \mathrm{~h}$ pre-incubation with $20 \mu \mathrm{M}$ calpain inhibitor III (CiIII) significantly preserved Kidins220-C33 $(126.2 \pm 6.4 \%, \mathrm{p}<0.05)$ and to a lesser extent Kidins220-C32 levels $(66.4 \pm 4.8 \%)$ relative to untreated cultures (Figure 7D). As previously described by our group (15), CiIII treatment prevented the appearance of Kidins220 Nt-7/8 fragment associated to NMDA-induced processing (Supplementary Figure 4D). All these inhibitors hampered the formation of spectrin BDPs, indicative of calpain activity blockage (Figure 7B, 7C and 7D, right panels). Together, our results show that Kidins220-C33 isoform is a calpain substrate, susceptible to degradation in excitotoxic conditions.

\section{DISCUSION}

This is the first study investigating possible alterations in Kidins220 alternative splicing isoforms in human pathology, and in particular in HD. We have examined the expression of the conventional Kidins220-C32 and the newly identified Kidins220-C33, the only two alternative C-terminal exon splice-variants expressed in the adult brain (43). Analysis of brain areas from human HD necropsies and the R6/1 mouse model demonstrate a clear differential regulation of these isoforms.

Kidins220-C33 is the most affected variant and its protein appears highly reduced in the striatum of HD patients with a tendency to decrease in the cerebral cortex. Similarly, brain from R6/1 mice showed a selective downregulation of Kidins220-C33 that begins at early stages of disease progression in striatum and cerebral cortex and becomes accentuated as the disease progresses in all brain regions analyzed. Given that the mRNA levels for Kidins220-C33 are unchanged in these brain structures in human and mice, C33-HD-associated decrease is likely to be consequence of protein degradation. 
In contrast, Kidins220-C32 protein is not diminished in striatum or cerebral cortex from HD patients and R6/1 mice. However, we observe enhanced Kidins220-C32 transcription in HD human cortex and R6/1 striatum that does not correlate with protein upregulation. Several mechanism could explain these results, such us alterations in mRNA stabilization and/or splicing that could be accompanied by translation deficiencies and/or increased turnover of the protein, as well as dysfunctional proteolysis which are well documented in HD (56). Recently, an increase in Kidins220C32 levels have been reported in cortex and hippocampus from HD patients, and in the hippocampus of HD mice models (27). In this report, published by Lopez-Benito et al., striatum, the brain region more vulnerable to damage in $\mathrm{HD}$, was not evaluated in animal or human samples. In both studies there are no appreciable variations in the cortex of the different HD mouse models relative to control mice. The apparent discrepancies in the results obtained from human cortices by us and by Lopez-Benito et al. could depend on differences between the patient samples, such as post-mortem interval, storage or lysate preparation. In this regard, Kidins220-C32 is highly insoluble, and associates to lipid-rafts $(5,23,42)$ and to several cytoskeletal components $(3,20$, 36), thus making its extraction highly dependent on the tissue, operator, and conditions. Whilst we did not analyze human hippocampus, we have detected increases in Kidins220-C32 in the hippocampus of R6/1 mice, in agreement with the other authors' findings (27). In our model, these rises are transient, being apparent at early symptomatic stages but disappearing at later stages of the disease. These differences may rely on the HD mouse model used in the two studies and the age or disease stage of the animals examined. In this context, separation of R6/1 mice in two well-defined groups (3.5 and 7.5 months), corresponding to early and late symptomatic stages was not carried out in the previous report. Lopez-Benito et al. analysed hippocampi from 8- 
month-old $H d h^{Q 7 / Q 111}$ knock-in mutants (51) and R6/1 mice in a single group constituted by four animals ranging from 4 to 7 months. In addition, R6/1 and $H d h^{Q 7 / Q 111}$ mice differ in the number of polyglutamine repeats (115 and 111, respectively). Together, these facts might account for the observed differences. Here we also detect the presence of Kidins220-C32 both in neurons and astrocytes. This is the first report showing Kidins220-C32 expression is not only restricted to neurons but is also present in astrocytes, as assessed by GFAP-coimmunostaining. Astrogliosis is a hallmark of HD in human brain (12), and the hippocampus of young R6/1 mice contains increased infiltration of GFAP-positive astrocytes (34). It could therefore be plausible that astrocytes may account for the rising in Kidins220-C32 levels in the hippocampus in different HD mouse models. The role of Kidins220-C32 in astrocytes biology under physiological and pathological conditions will surely be an interesting area of research for the future.

Kidins220-C33 downregulation in HD takes place in neurons, where the expression of this variant is mainly confined. This decrease is detectable in striatum from early symptomatic stages in R6/1 mice, suggesting a key role of Kidins220-C33 in the etiology of the disorder. We do not observe changes in Kidins220-C33 mRNA levels in the striatum of R6/1 mice at late stages, when the most enhanced effects on the protein were detected, or in cerebral cortex or striatum from HD patients. These data suggest that Kidins220-C33 downregulation may rely on posttranscriptional processes. Indeed, our data support the notion that calpain proteolysis might be involved in Kidins220-C33 decrease in HD neurons. In this context, post-mortem calpain activation in human brain samples did not influence our results since regression analysis discards a negative correlation between relative levels of Kidins220-C33 and post-mortem interval (Supplementary Figure 5). Our findings regarding increased spectrin BDPs reflect 
calpain overactivation in human HD and R6/1 mice brain samples. Over the past years, several lines of evidence have conclusively demonstrated augmented calpain expression or activity in human HD brain $(13,25)$ and different neurodegenerative striatal models: from pharmacological models that employ administration of the mitochondrial inhibitor 3-nitropropionic acid in rats (2) to those caused by the deleterious effect of $\mathrm{mHtt}$ expression in different transgenic HD mouse models $(9,14,38,41,50)$. Moreover, preclinical studies aimed to lower calpain activity in these models have demonstrated beneficial effects in flies, fishes and rodents $(2,8,33,50,52)$, suggesting a possible common mechanism. Accordingly, depleting the endogenous calpain inhibitor calpastatin, in a mHtt knock-in mouse model aggravates disease hallmarks (49). The intracellular pathways underlying the neurotoxic effect induced by overactivated calpain have been associated with altered cleavage of $\mathrm{mHtt}(14,25)$ and with defective autophagy $(33,52)$. Analysis using Kid-Nt antibody in R6/1 brain revealed increased levels of a band that could correspond to Nt-7/8 fragment. The clear decrease of Kidins220-C33 levels in HD, being Kidins220-C32 protein unchanged, point to C33 isoform as the one originating these fragments and the most affected by excessive calpain activity characteristic of the disease. Despite the impossibility to distinguish the isoform origin of the putative $\mathrm{Nt}-7 / 8$, this is a relevant result because it may be indicative of an augmented proteolytic processing of Kidins220 in HD brain. Together these data support the hypothesis that Kidins220 calpain cleavage could contribute to the pathogenic alterations observed in HD brain. However, further studies are necessary to elucidate whether Kidins220-C33 degradation found in HD may directly cause neuronal damage as a consequence of excessive calpain proteolysis, opening a new therapeutic window for treating this neurodegenerative disease.

This article is protected by copyright. All rights reserved. 
To date, only one article has been published related to Kidins220-C33 (43). The observation that overexpression of Kidins220-C33 in PC12 cells and hippocampal neurons sequesters endogenous Kidins220-C32 in the perinuclear region pointed to this variant as a dominant-negative version of Kidins220-C32, which alters its physiological distribution and function $(3,43)$. In addition to NT-signaling, we have previously reported that Kidins220-C32 is key to neuronal survival downstream NMDARs (16, 29).

It was therefore unexpected to discover that deficiencies in Kidins220-C33 are linked to neurodegenerative scenarios, such as that provoked by $\mathrm{mHtt}$ in HD, suggesting a novel neuroprotective role of this variant. SINO syndrome, caused by mutations in KIDINS220 gene, has been so far related to Kidins220-C32 loss-of-function and the generation of truncated derivatives of this isoform $(24,53)$. Indeed, it has been suggested that these truncated versions, that might resemble Kidins220-C33 due to their lack of critical regions for NT-signaling, could be deleterious to neurons.

However, these mutations would equally compromise the expression of the full-length version of Kidins220-C33, since exon 33 follows exon 32 position. Our results strongly support a fundamental function of Kidins220-C33 for neuronal survival due to yet unexplored exon33-specific signaling pathways, and encourage future research in this direction. Possible changes in this variant and its association to other neurodegenerative diseases deserve further investigation.

\section{ACKNOWLEDGEMENTS}

This work was supported by the Spanish Ministerio de Ciencia, Innovación y Universidades (MCIU) grants to T.I. (SAF2017-88885-R), J.J.L. (SAF2015-65371-R) and M.R.C. (SAF2017-88881-R); by B2017/BMD-3700 NEUROMETAB-CM 
(Comunidad de Madrid, Madrid, Spain) to T.I. and institutional grants to CBMSO from Fundación Ramón Areces and Fundación Banco de Santander to J.J.L. T.I. and J.J.L. are also funded by Centro de Investigación Biomédica en Red de Enfermedades Neurodegenerativas (CIBERNED) and CIBERNED cooperative project 2015-2/06 (Instituto de Salud Carlos III, Spain). GS work was supported by the Wellcome Trust Senior Investigator Award (107116/Z/15/Z), the European Union's Horizon 2020 Research and Innovation programme under grant agreement 739572 and a UK Dementia Research Institute Foundation award. A.S.-S. was funded by a contract from CIBERNED-2015-2/06. The cost of this publication has been paid in part by FEDER (European Funds for Regional Development) funds. We also thank Marina Prudencio Sánchez-Carralero technical support and that of the Confocal Microscopy service at IIBm, and the Genomic and Massive Sequencing services at CBMSO.

\section{CONFLICT OF INTEREST}

The authors declare no conflict of interest

\section{REFERENCES}

1. Arevalo JC, Yano H, Teng KK, Chao MV (2004) A unique pathway for sustained neurotrophin signaling through an ankyrin-rich membrane-spanning protein. EMBO J.23(12):2358-68.

2. Bizat N, Hermel JM, Boyer F, Jacquard C, Creminon C, Ouary S, Escartin C, Hantraye P, Kajewski S, Brouillet E (2003) Calpain is a major cell death effector in selective striatal degeneration induced in vivo by 3-nitropropionate: implications for Huntington's disease. J Neurosci.23(12):5020-30.

This article is protected by copyright. All rights reserved. 
3. Bracale A, Cesca F, Neubrand VE, Newsome TP, Way M, Schiavo G (2007) Kidins220/ARMS is transported by a kinesin-1-based mechanism likely to be involved in neuronal differentiation. Mol Biol Cell.18(1):142-52.

4. Brito V, Puigdellivol M, Giralt A, del Toro D, Alberch J, Gines S (2013) Imbalance of $\mathrm{p} 75(\mathrm{NTR}) / \mathrm{TrkB}$ protein expression in Huntington's disease: implication for neuroprotective therapies. Cell Death Dis.4:e595.

5. Cabrera-Poch N, Sanchez-Ruiloba L, Rodriguez-Martinez M, Iglesias T (2004) Lipid raft disruption triggers protein kinase C and Src-dependent protein kinase D activation and Kidins220 phosphorylation in neuronal cells. $\mathbf{J}$ Biol Chem.279(27):28592-602.

6. Cesca F, Yabe A, Spencer-Dene B, Arrigoni A, Al-Qatari M, Henderson D, Phillips H, Koltzenburg M, Benfenati F, Schiavo G (2011) Kidins220/ARMS is an essential modulator of cardiovascular and nervous system development. Cell Death Dis.2:e226.

7. Chang MS, Arevalo JC, Chao MV (2004) Ternary complex with Trk, p75, and an ankyrin-rich membrane spanning protein. J Neurosci.78(2):186-92.

8. Clemens LE, Weber JJ, Wlodkowski TT, Yu-Taeger L, Michaud M, Calaminus C, Eckert SH, Gaca J, Weiss A, Magg JC, Jansson EK, Eckert GP, Pichler BJ, Bordet T, Pruss RM, Riess O, Nguyen HP (2015) Olesoxime suppresses calpain activation and mutant huntingtin fragmentation in the BACHD rat. Brain.138(Pt 12):3632-53.

9. Cowan CM, Fan MM, Fan J, Shehadeh J, Zhang LY, Graham RK, Hayden MR, Raymond LA (2008) Polyglutamine-modulated striatal calpain activity in YAC transgenic huntington disease mouse model: impact on NMDA receptor function and toxicity. J Neurosci.28(48):12725-35.

This article is protected by copyright. All rights reserved. 
10. Crook ZR, Housman D (2011) Huntington's disease: can mice lead the way to treatment? Neuron.69(3):423-35.

11. Davies SW, Turmaine M, Cozens BA, DiFiglia M, Sharp AH, Ross CA, Scherzinger E, Wanker EE, Mangiarini L, Bates GP (1997) Formation of neuronal intranuclear inclusions underlies the neurological dysfunction in mice transgenic for the HD mutation. Cell.90(3):537-48.

12. Faideau M, Kim J, Cormier K, Gilmore R, Welch M, Auregan G, Dufour N, Guillermier M, Brouillet E, Hantraye P, Deglon N, Ferrante RJ, Bonvento G (2010) In vivo expression of polyglutamine-expanded huntingtin by mouse striatal astrocytes impairs glutamate transport: a correlation with Huntington's disease subjects. Hum Mol Genet.19(15):3053-67.

13. Gafni J, Ellerby LM (2002) Calpain activation in Huntington's disease. J Neurosci.22(12):4842-9.

14. Gafni J, Hermel E, Young JE, Wellington CL, Hayden MR, Ellerby LM (2004) Inhibition of calpain cleavage of huntingtin reduces toxicity: accumulation of calpain/caspase fragments in the nucleus. J Biol Chem.279(19):20211-20.

15. Gamir-Morralla A, Belbin O, Fortea J, Alcolea D, Ferrer I, Lleo A, Iglesias T (2017) Kidins220 Correlates with Tau in Alzheimer's Disease Brain and Cerebrospinal Fluid. J Alzheimers Dis.55(4):1327-33.

16. Gamir-Morralla A, Lopez-Menendez C, Ayuso-Dolado S, Tejeda GS, Montaner J, Rosell A, Iglesias T, Diaz-Guerra M (2015) Development of a neuroprotective peptide that preserves survival pathways by preventing Kidins220/ARMS calpain processing induced by excitotoxicity. Cell Death Dis.6:e1939.

This article is protected by copyright. All rights reserved. 
17. Gines S, Bosch M, Marco S, Gavalda N, Diaz-Hernandez M, Lucas JJ, Canals JM, Alberch J (2006) Reduced expression of the TrkB receptor in Huntington's disease mouse models and in human brain. Eur J Neurosci.23(3):649-58.

18. Girling KD, Wang YT (2016) Neuroprotective strategies for NMDAR-mediated excitotoxicity in Huntington's Disease. Front Biol.11(6):439-58.

19. Group THsDCR (1993) A novel gene containing a trinucleotide repeat that is expanded and unstable on Huntington's disease chromosomes. . Cell.72(6):971-83.

20. Higuero AM, Sanchez-Ruiloba L, Doglio LE, Portillo F, Abad-Rodriguez J, Dotti CG, Iglesias T (2010) Kidins220/ARMS modulates the activity of microtubuleregulating proteins and controls neuronal polarity and development. J Biol Chem.285(2):1343-57.

21. Hisata S, Sakisaka T, Baba T, Yamada T, Aoki K, Matsuda M, Takai Y (2007) Rap1-PDZ-GEF1 interacts with a neurotrophin receptor at late endosomes, leading to sustained activation of Rap1 and ERK and neurite outgrowth. J Cell Biol.178(5):843-60.

22. Iglesias T, Cabrera-Poch N, Mitchell MP, Naven TJ, Rozengurt E, Schiavo G (2000) Identification and cloning of Kidins220, a novel neuronal substrate of protein kinase D. J Biol Chem.275(51):40048-56.

23. Jean-Mairet RM, Lopez-Menendez C, Sanchez-Ruiloba L, Sacristan S, RodriguezMartinez M, Riol-Blanco L, Sanchez-Mateos P, Sanchez-Madrid F, RodriguezFernandez JL, Campanero MR, Iglesias T (2011) The neuronal protein Kidins220/ARMS associates with ICAM-3 and other uropod components and regulates T-cell motility. Eur J Immunol.41(4):1035-46.

24. Josifova DJ, Monroe GR, Tessadori F, de Graaff E, van der Zwaag B, Mehta SG, Study DDD, Harakalova M, Duran KJ, Savelberg SM, Nijman IJ, Jungbluth H, 
Hoogenraad CC, Bakkers J, Knoers NV, Firth HV, Beales PL, van Haaften G, van Haelst MM (2016) Heterozygous KIDINS220/ARMS nonsense variants cause spastic paraplegia, intellectual disability, nystagmus, and obesity. Hum Mol Genet.25(11):2158-67.

25. Kim YJ, Yi Y, Sapp E, Wang Y, Cuiffo B, Kegel KB, Qin ZH, Aronin N, DiFiglia M (2001) Caspase 3-cleaved N-terminal fragments of wild-type and mutant huntingtin are present in normal and Huntington's disease brains, associate with membranes, and undergo calpain-dependent proteolysis. Proc Natl Acad Sci U S A.98(22):12784-9.

26. Kong H, Boulter J, Weber JL, Lai C, Chao MV (2001) An evolutionarily conserved transmembrane protein that is a novel downstream target of neurotrophin and ephrin receptors. J Neurosci.21(1):176-85.

27. Lopez-Benito S, Sanchez-Sanchez J, Brito V, Calvo L, Lisa S, Torres-Valle M, Palko ME, Vicente-Garcia C, Fernandez-Fernandez S, Bolanos JP, Gines S, Tessarollo L, Arevalo JC (2018) Regulation of BDNF Release by ARMS/Kidins220 through Modulation of Synaptotagmin-IV Levels. J Neurosci.38(23):5415-28.

28. Lopez-Menendez C, Gamir-Morralla A, Jurado-Arjona J, Higuero AM, Campanero MR, Ferrer I, Hernandez F, Avila J, Diaz-Guerra M, Iglesias T (2013) Kidins220 accumulates with tau in human Alzheimer's disease and related models: modulation of its calpain-processing by GSK3beta/PP1 imbalance. Hum Mol Genet.22(3):46682.

29. Lopez-Menendez C, Gascon S, Sobrado M, Vidaurre OG, Higuero AM, RodriguezPena A, Iglesias T, Diaz-Guerra M (2009) Kidins220/ARMS downregulation by 
excitotoxic activation of NMDARs reveals its involvement in neuronal survival and death pathways. J Cell Sci.122(Pt 19):3554-65.

30. Ma Q, Yang J, Li T, Milner TA, Hempstead BL (2015) Selective reduction of striatal mature BDNF without induction of proBDNF in the zQ175 mouse model of Huntington's disease. Neurobiol Dis.82:466-77.

31. Mangiarini L, Sathasivam K, Seller M, Cozens B, Harper A, Hetherington C, Lawton M, Trottier Y, Lehrach H, Davies SW, Bates GP (1996) Exon 1 of the HD gene with an expanded CAG repeat is sufficient to cause a progressive neurological phenotype in transgenic mice. Cell.87(3):493-506.

32. Martin JB, Gusella JF (1986) Huntington's disease. Pathogenesis and management. N Engl J Med.315(20):1267-76.

33. Menzies FM, Garcia-Arencibia M, Imarisio S, O'Sullivan NC, Ricketts T, Kent BA, Rao MV, Lam W, Green-Thompson ZW, Nixon RA, Saksida LM, Bussey TJ, O'Kane CJ, Rubinsztein DC (2015) Calpain inhibition mediates autophagydependent protection against polyglutamine toxicity. Cell Death Differ.22(3):43344.

34. Miguez A, Garcia-Diaz Barriga G, Brito V, Straccia M, Giralt A, Gines S, Canals JM, Alberch J (2015) Fingolimod (FTY720) enhances hippocampal synaptic plasticity and memory in Huntington's disease by preventing p75NTR up-regulation and astrocyte-mediated inflammation. Hum Mol Genet.24(17):4958-70.

35. Neubrand VE, Cesca F, Benfenati F, Schiavo G (2012) Kidins220/ARMS as a functional mediator of multiple receptor signalling pathways. J Cell Sci.125(Pt 8):1845-54.

This article is protected by copyright. All rights reserved. 
36. Neubrand VE, Thomas C, Schmidt S, Debant A, Schiavo G (2010) Kidins220/ARMS regulates Rac1-dependent neurite outgrowth by direct interaction with the RhoGEF Trio. J Cell Sci.123(Pt 12):2111-23.

37. Nguyen DH, Zhou T, Shu J, JH M (2013) Quantifying chromogen intensity in immunohistochemistry via reciprocal intensity. Cancer InCytes.2(1):e.

38. Paoletti P, Vila I, Rife M, Lizcano JM, Alberch J, Gines S (2008) Dopaminergic and glutamatergic signaling crosstalk in Huntington's disease neurodegeneration: the role of p25/cyclin-dependent kinase 5. J Neurosci.28(40):10090-101.

39. Perez-Navarro E, Alberch J, Neveu I, Arenas E (1999) Brain-derived neurotrophic factor, neurotrophin-3 and neurotrophin- $4 / 5$ differentially regulate the phenotype and prevent degenerative changes in striatal projection neurons after excitotoxicity in vivo. Neurosci.91(4):1257-64.

40. Perez-Navarro E, Canudas AM, Akerund P, Alberch J, Arenas E (2000) Brainderived neurotrophic factor, neurotrophin-3, and neurotrophin-4/5 prevent the death of striatal projection neurons in a rodent model of Huntington's disease. J Neurochem.75(5):2190-9.

41. Rajput PS, Kharmate G, Norman M, Liu SH, Sastry BR, Brunicardi CF, Kumar U (2011) Somatostatin receptor 1 and 5 double knockout mice mimic neurochemical changes of Huntington's disease transgenic mice. PLoS One.6(9):e24467.

42. Riol-Blanco L, Iglesias T, Sanchez-Sanchez N, de la Rosa G, Sanchez-Ruiloba L, Cabrera-Poch N, Torres A, Longo I, Garcia-Bordas J, Longo N, Tejedor A, Sanchez-Mateos P, Rodriguez-Fernandez JL (2004) The neuronal protein Kidins 220 localizes in a raft compartment at the leading edge of motile immature dendritic cells. Eur J Immunol.34(1):108-18.

This article is protected by copyright. All rights reserved. 
43. Schmieg N, Thomas C, Yabe A, Lynch DS, Iglesias T, Chakravarty P, Schiavo G (2015) Novel Kidins220/ARMS Splice Isoforms: Potential Specific Regulators of Neuronal and Cardiovascular Development. PLoS One.10(6):e0129944.

44. Simmons DA (2017) Modulating Neurotrophin Receptor Signaling as a Therapeutic Strategy for Huntington's Disease. J Huntingtons Dis.6(4):303-25.

45. Simmons DA, Longo FM, Massa SM (2017) Neurotrophin Receptor Signaling as a Therapeutic Target for Huntington's Disease. CNS Neurol Disord Drug Targets.16(3):291-302.

46. Sorimachi Y, Harada K, Yoshida K (1996) Involvement of calpain in postmortem proteolysis in the rat brain. Forensic Sci Int.81(2-3):165-74.

47. Vonsattel JP, DiFiglia M (1998) Huntington disease. J Neuropathol Exp Neurol.57(5):369-84.

48. Vonsattel JP, Myers RH, Stevens TJ, Ferrante RJ, Bird ED, Richardson EP, Jr. (1985) Neuropathological classification of Huntington's disease. J Neuropathol Exp Neurol.44(6):559-77.

49. Weber JJ, Kloock SJ, Nagel M, Ortiz-Rios MM, Hofmann J, Riess O, Nguyen HP (2018) Calpastatin ablation aggravates the molecular phenotype in cell and animal models of Huntington disease. Neuropharmacology.133:94-106.

50. Weber JJ, Ortiz Rios MM, Riess O, Clemens LE, Nguyen HP (2016) The calpainsuppressing effects of olesoxime in Huntington's disease. Rare Dis.4(1):e1153778.

51. Wheeler VC, Auerbach W, White JK, Srinidhi J, Auerbach A, Ryan A, Duyao MP, Vrbanac V, Weaver M, Gusella JF, Joyner AL, MacDonald ME (1999) Lengthdependent gametic CAG repeat instability in the Huntington's disease knock-in mouse. Hum Mol Genet.8(1):115-22.

This article is protected by copyright. All rights reserved. 
52. Williams A, Sarkar S, Cuddon P, Ttofi EK, Saiki S, Siddiqi FH, Jahreiss L, Fleming A, Pask D, Goldsmith P, O'Kane CJ, Floto RA, Rubinsztein DC (2008) Novel targets for Huntington's disease in an mTOR-independent autophagy pathway. Nat Chem Biol.4(5):295-305.

53. Yang L, Zhang W, Peng J, Yin F (2018) Heterozygous KIDINS220 mutation leads to spastic paraplegia and obesity in an Asian girl. Eur J Neurol.25(5):e53-e4.

54. Zuccato C, Cattaneo E (2007) Role of brain-derived neurotrophic factor in Huntington's disease. Prog Neurobiol.81(5-6):294-330.

55. Zuccato C, Cattaneo E (2009) Brain-derived neurotrophic factor in neurodegenerative diseases. Nat Rev Neurol.5(6):311-22.

56. Zuccato C, Valenza M, Cattaneo E (2010) Molecular mechanisms and potential therapeutical targets in Huntington's disease. Physiol Rev.90(3):905-81.

\section{DATA AVAILABILITY STATEMENT}

The datasets generated and/or analysed during the current study are available from the corresponding authors on reasonable request.

\section{FIGURE LEGENDS}

Figure 1. HD patients present reduced striatal protein levels of Kidins220-C33. (A) Scheme showing main domains of Kidins220 isoforms and binding sites of Kidins220C32 (black) and Kidins220-C33 (grey) antibodies. Note that C33 C-terminal region is codified by exon 33 (E33) that substitutes C-terminal amino acids encoded by exon 32 in Kidins220-C32. KAP: Kidins220/ARMS and PifA NTP-ase; PR: Proline-Rich; SAM: Sterile alpha-motif; KIM: Kinesin Interacting Motif; PDZ-L: PDZ-ligand. (B) Representative immunoblot of Kidins220-C32 and Kidins220-C33 and quantification of 
protein levels in homogenates from striatum and cerebral cortex necropsies from HD patients (n=6-10) and control non-affected individuals $(n=5-10)$. Levels of $\beta$-actin were used as loading control for normalization purposes. (C) qRT-PCR analysis of Kidins220-C32 and Kidins220-C33 mRNA from striatum and cortex of HD patients $(\mathrm{n}=7$ and $n=8)$ and non-affected individuals $(\mathrm{n}=5$ and $\mathrm{n}=8)$. Data are represented as means +/- S.E.M. *p $<0.05$ or **p $<0.01$ using unpaired Student's t-test.

Figure 2. Selective protein downregulation of Kidins220-C33 in R6/1 mice brain. (A, B) Representative immunoblot of Kidins220-C32 and Kidins220-C33 and quantification of protein levels in homogenates from striatum, cerebral cortex and hippocampus of 3.5-month-old or 7.5-month-old R6/1 $(n=6)$ and wild type (WT) mice $(n=7)$ of the same ages. Levels of $\beta$-actin were used as loading control for normalization purposes. (C) qRT-PCR analysis of Kidins220-C32 and Kidins220-C33 mRNA from striatum of 7.5-month-old R6/1 $(n=6)$ and WT $(n=7)$ mice. Data are represented as means + /- S.E.M. $* \mathrm{p}<0.05, * * \mathrm{p}<0.01$ or $* * * \mathrm{p}<0.001$ using unpaired Student's t-test.

Figure 3. Kidins220-C33 is expressed mainly in neurons and decreases in HD mouse brain. (A) Representative confocal microscopy images corresponding to the hippocampal CA1 region (GCL, granular cell layer) in brain slices from WT mice triple-stained with antibodies against Kidins220-C32 or Kidins220-C33 (red channel) together with neuronal (NeuN, green channel) and astrocytic (GFAP, purple channel) markers. Arrow and arrow head indicate neurons or astrocytes, respectively. DAPI nuclear staining is also shown. Scale bar: $50 \mu \mathrm{m}$. (B) Quantification of astrocytes (GFAP-positive cells) and neurons (NeuN-positive cells) expressing Kidins220-C32 or Kidins220-C33 isoforms ( $\mathrm{n}=4$ animals per group). (C) Kidins220-C32 and Kidins220C33 DAB immunohistochemistry in cerebral cortex sections from 7.5-month-old WT and R6/1 mice. Representative images containing all cortical layers (upper panels, scale 
bar: $50 \mu \mathrm{m}$ ) and higher magnification are depicted (lower panels, scale bar: $100 \mu \mathrm{m}$ ).

(D) Chromogen detection was quantified and expressed as DAB-staining reciprocal intensity (Arbitrary Units, A.U.) from sections using antibodies against Kidins220-C32 (upper graph) or Kidins220-C33 (lower graph) (n=3 animals per group). (E) Representative confocal microscopy images of Kidins220-C33 staining (red channel) in neurons (NeuN+, green channel) in cerebral cortex of WT and early symptomatic R6/1 mice (scale bar: $100 \mu \mathrm{m}$ ). Zoom images from boxed regions are also shown (scale bar: $25 \mu \mathrm{m})$. (F) Quantification of Kidins220-C33 staining in cortical neurons of WT compared to $\mathrm{R} 6 / 1$ ( $\mathrm{n}=4$ animals per group). (G) Representative confocal microscopy images corresponding to brain slices from 7.5-month-old WT and R6/1 mice doublestained for Kidins220 C-terminal splice variants (red channel) and $\mathrm{mHtt}$ (green channel). Scale bar: $20 \mu \mathrm{m}$. Nuclear staining with DAPI is also shown. Data are represented as means $+/$ - S.E.M. ${ }^{*} \mathrm{p}<0.05,{ }^{*} \mathrm{p}<0.01$ or $* * * \mathrm{p}<0.001$ using unpaired Student's t-test.

Figure 4. Identification of Kidins220-C33 variant in rat neurons. (A) Nucleotide and amino acid sequence alignment of mouse and rat exon 33. Nucleotide mismatches are represented in red. (B) Representative immunoblot showing the specific detection of rat Kidins220-C33 in lysates from different brain structures (St, striatum. Hp, hippocampus. $\mathrm{Cb}$, cerebellum. $\mathrm{CxA}$, anterior cerebral cortex. $\mathrm{CxP}$, posterior cerebral cortex) using the antibody generated to detect the murine variant. Lysates from mice cerebral cortex were used as a positive control (+ Control). (C) Rat primary neurons cultured on coverslips were co-stained with antibodies against Kidins220-C33 (red channel) and the neuronal marker NeuN (green channel), and counterstained with nuclear marker DAPI. Scale bar: $20 \mu \mathrm{m}$.

This article is protected by copyright. All rights reserved. 
Figure 5. Inverse correlation between levels of Kidins220 isoforms and post-mortem

time. (A) Representative immunoblot of Kidins220 variants in homogenates from mouse brain harvested at different post-mortem intervals $(\mathrm{t}=0-24 \mathrm{~h})$. Isoform-specific $\mathrm{C}$ terminal antibodies (Kidins220-C32 and Kidins220-C33) or an antibody recognizing their common $\mathrm{N}$-terminal region (Kid-Nt) were used. Graphs show the quantification of full-length Kidins220-C32 and Kidins220-C33 protein levels (B) and the processing derived-fragments Nt-5/6 (80-85 kDa, middle panel in C) and Nt-7/8 (109-115kDa, bottom panel in C). Spectrin full-length (FL) and calpain-breakdown products (BDPs) are also shown and BDPs quantified ( $\mathbf{C}$, Top panel). Levels of $\beta$-actin were used as loading control for normalization purposes. Data are represented as means +/- S.E.M. $* \mathrm{p}<0.05, * * \mathrm{p}<0.01$ or $* * * \mathrm{p}<0.001$ using unpaired Student's t-test.

Figure 6. Increased calpain activity HD brain. Representative immunoblot of spectrin FL and BDPs and quantification of BDPs protein levels in homogenates from (A) striatum $(n=7)$ and cerebral cortex $(n=6)$ necropsies from HD patients and control non-affected individuals or from $(\mathbf{B})$ striatum of 3.5-month-old R6/1 and WT mice (n=6 per group). (C) Representative immunoblot of Kid-Nt and quantification of putative Nt7/8 fragments in homogenates from striatum and cerebral cortex of 7.5-month-old R6/1 $(n=4)$ and WT mice $(n=6)$. Levels of $\beta$-actin were used as loading control for normalization purposes. Data are represented as means +/- S.E.M. ${ }^{*} \mathrm{p}<0.05, * * \mathrm{p}<0.01$ or $* * * \mathrm{p}<0.001$ using unpaired Student's t-test.

Figure 7. Calpain-dependent downregulation of Kidins220-C33 splice variant in excitotoxic conditions mediated by NMDARs overstimulation and $\mathrm{Ca}^{2+}$ entry. (A) Kidins220-C32 and Kidins220-C33 immunoblot analysis of cultured primary mature cortical neurons stimulated with excitotoxic concentrations of NMDA $(100 \mu \mathrm{M})$ plus its 
co-agonist glycine $(10 \mu \mathrm{M})$ (a treatment referred hereafter as "NMDA") for various periods of time. Spectrin FL and BDPs are also shown. (B-D) Kidins220 isoforms and spectrin immunoblot analysis of neurons pre-treated for $1 \mathrm{~h}$ with $(\mathbf{B})$ the NMDAR antagonist DL-AP5, $(\mathbf{C})$ the $\mathrm{Ca}^{2+}$ chelator EGTA or (D) the calpain inhibitor CiIII and then stimulated with NMDA for $4 \mathrm{~h}$. Graphs on the right represent the quantification of Kidins220 alternative C-terminal variants or spectrin BDPs immunoblot signal relative to that of the loading control neural-specific enolase (NSE). $n=3-4$ independent experiments. Data are given as means +/- S.E.M. n.s, not significant; ${ }^{*} \mathrm{p}<0.05$, $* * p<$ 0.01 or ***p $<0.001$ using 1-way ANOVA, followed by Bonferroni's post-hoc test.

This article is protected by copyright. All rights reserved. 
Table 1. Case information for HD and control cases

\begin{tabular}{|c|c|c|c|c|c|}
\hline Diagnosis & $\begin{array}{l}\text { Vonsattel } \\
\text { grade }\end{array}$ & Sex & $\begin{array}{l}\text { Age } \\
\text { (years) }\end{array}$ & PMI & $\begin{array}{l}\text { Structure } \\
\text { analyzed }\end{array}$ \\
\hline HD & $\mathrm{n} / \mathrm{a}$ & $\mathrm{M}$ & 44 & $\mathrm{n} / \mathrm{a}$ & St \\
\hline HD & $\mathrm{n} / \mathrm{a}$ & M & 43 & $\mathrm{n} / \mathrm{a}$ & St \\
\hline HD & $\mathrm{n} / \mathrm{a}$ & $\mathrm{F}$ & 68 & $\mathrm{n} / \mathrm{a}$ & St \\
\hline HD & 46, g. 3 & M & 57 & $7: 30$ & $\mathrm{St}$ \\
\hline HD & 54 & M & 49 & $5: 45$ & St \\
\hline HD & 47, g. $2-3$ & $\mathrm{~F}$ & 50 & $5: 40$ & $\mathrm{St}$ \\
\hline HD & 44, g. 1 & M & 59 & $5: 05$ & St \\
\hline HD & $\mathrm{n} / \mathrm{a}$ & M & 71 & $10: 15$ & St, Cx \\
\hline HD & $\mathrm{n} / \mathrm{a}$ & $\mathrm{F}$ & 65 & $15: 15$ & St, Cx \\
\hline HD & $\mathrm{n} / \mathrm{a}$ & M & 68 & $4: 00$ & St, Cx \\
\hline HD & $\mathrm{n} / \mathrm{a}$ & M & 60 & $13: 05$ & $\mathrm{Cx}$ \\
\hline HD & $\mathrm{n} / \mathrm{a}$ & $\mathrm{F}$ & 72 & $7: 00$ & $\mathrm{Cx}$ \\
\hline HD & $\mathrm{n} / \mathrm{a}$ & $\mathrm{F}$ & 72 & $17: 00$ & $\mathrm{Cx}$ \\
\hline Control & - & M & 68 & 8 & $\mathrm{St}$ \\
\hline Control & - & M & 56 & $\mathrm{n} / \mathrm{a}$ & St \\
\hline Control & - & $\mathrm{F}$ & 58 & $\mathrm{n} / \mathrm{a}$ & $\mathrm{St}$ \\
\hline Control & - & $\mathrm{F}$ & 70 & $6: 15$ & St \\
\hline Control & - & M & 55 & $7: 30$ & St \\
\hline Control & - & M & 51 & $7: 45$ & St \\
\hline Control & - & M & 76 & $6: 45$ & $\mathrm{St}$ \\
\hline Control & - & $\mathrm{n} / \mathrm{a}$ & $\mathrm{n} / \mathrm{a}$ & $\mathrm{n} / \mathrm{a}$ & St, Cx \\
\hline Control & - & $\mathrm{n} / \mathrm{a}$ & $\mathrm{n} / \mathrm{a}$ & $\mathrm{n} / \mathrm{a}$ & St, Cx \\
\hline Control & - & $\mathrm{n} / \mathrm{a}$ & $\mathrm{n} / \mathrm{a}$ & $\mathrm{n} / \mathrm{a}$ & St \\
\hline Control & - & M & 85 & $5: 45$ & $\mathrm{Cx}$ \\
\hline Control & - & $\mathrm{F}$ & 71 & $8: 30$ & $\mathrm{Cx}$ \\
\hline Control & - & $\mathrm{F}$ & 81 & $4: 00$ & $\mathrm{Cx}$ \\
\hline Control & - & $\mathrm{F}$ & 64 & $5: 00$ & $\mathrm{Cx}$ \\
\hline
\end{tabular}

n/a, not available. M, male. F, female. PMI, post-mortem interval (h). St, Striatum. Cx, Cerebral Cortex.

This article is protected by copyright. All rights reserved. 
Table 2. Primers used for qRT-PCR.

\begin{tabular}{lll}
\hline Target Genes & Forward $\left(\mathbf{5}^{\prime} \mathbf{- 3}^{\prime}\right)$ & Reverse $\mathbf{( 5}^{\prime} \mathbf{- 3}^{\prime} \mathbf{)}$ \\
\hline $\begin{array}{l}\text { Kidins220-C32 } \\
\text { (Human) }\end{array}$ & AGGTGCCCCTCGTCACAGTA & GGAATTGAGACTCGAAAGACTTGG \\
$\begin{array}{l}\text { Kidins220-C32 } \\
\text { (Mouse) }\end{array}$ & CCACGGCACAGTAATCTGAG & TGCACCTTATCAGTAAGCTTTGA \\
$\begin{array}{l}\text { Kidins220-C33 } \\
\text { (Human) }\end{array}$ & CCTGGATGAAGGTGCCCC & AGAGCTATCTATCTCAAGGCCAGC \\
$\begin{array}{l}\text { Kidins220-C33 } \\
\text { (Mouse) }\end{array}$ & CCACGGCACAGTAATCTGAG & GGATCTTCTGAACCGCTGTC \\
& & \\
\hline
\end{tabular}

\begin{tabular}{lll}
\hline $\begin{array}{l}\text { Housekeeping } \\
\text { Genes }\end{array}$ & Forward $\left(\mathbf{5}^{\prime} \mathbf{- 3}^{\prime}\right.$ ) & Reverse $\mathbf{( 5}^{\prime} \mathbf{3}^{\prime}$ ) \\
& & \\
\hline GAPDH (Human) & AGCCACATCGCTCAGACAC & CGCCCAATACGACCAAAT \\
$\beta$-actin (Human) & CAGGCACCAGGGCGTG & GTGAGGATGCCTCTCTTGCTCT \\
$\beta$-tubulin(Human) & CTTTGTGGAATGGATCCCCA & GACTGCCATCTTGAGGCCA \\
$\begin{array}{l}\text { 18S Ribosome } \\
\text { Subunit (Mouse) }\end{array}$ & CTCAACACGGGAAACCTCAC & CGCTCCACCAACTAAGAACG \\
GAPDH (Mouse) & CTCCCACTCTTCCACCTTCG & CATACCAGGAAATGAGCTTGACAA \\
$\beta$-actin (Mouse) & CTAAGGCCAACCGTGAAAAG & ACCAGAGGCATACAGGGACA \\
$\beta$-tubulin (Mouse) & GACCTATCATGGGGACAGTGA & CGGCTCTGGGAACATAGTTT \\
& &
\end{tabular}

This article is protected by copyright. All rights reserved. 
A

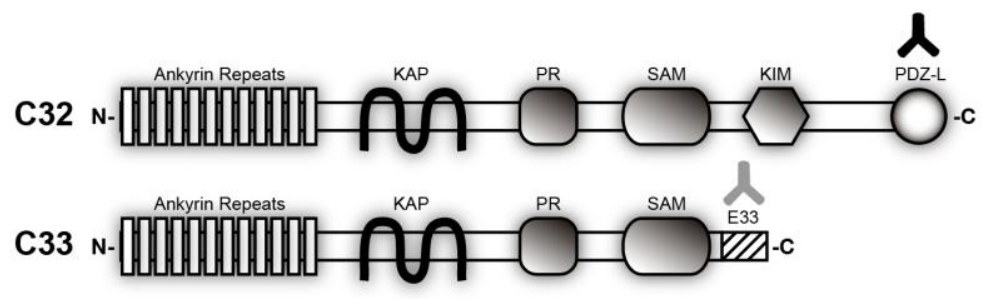

B
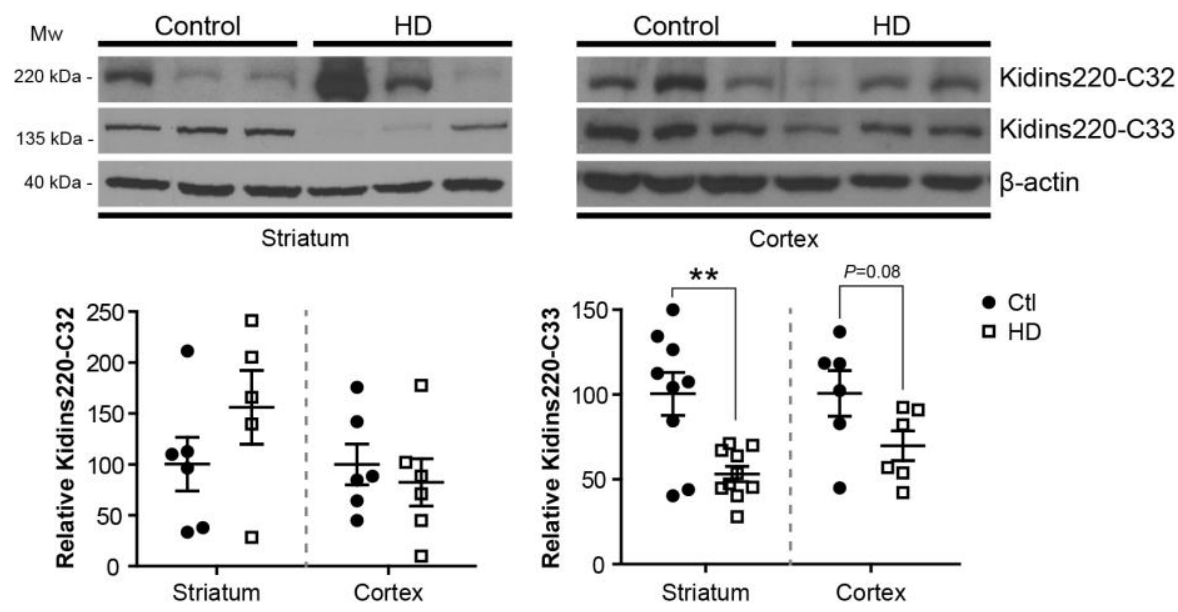

C
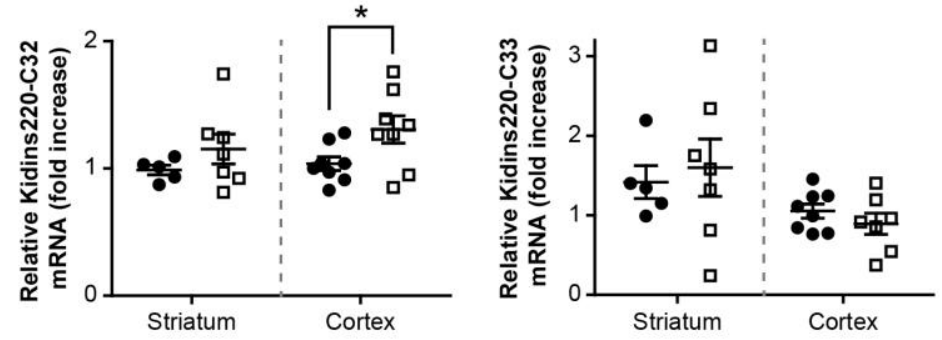

This article is protected by copyright. All rights reserved. 
A

3.5 Month

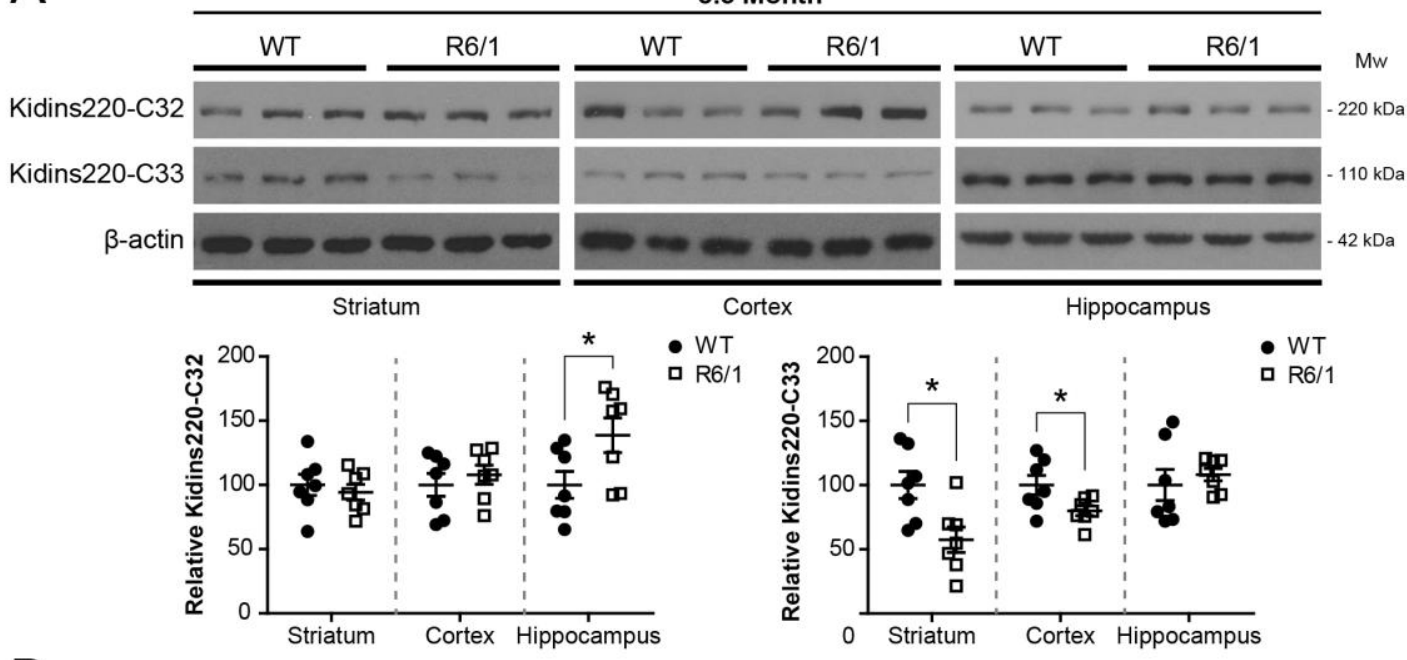

B

7.5 Month
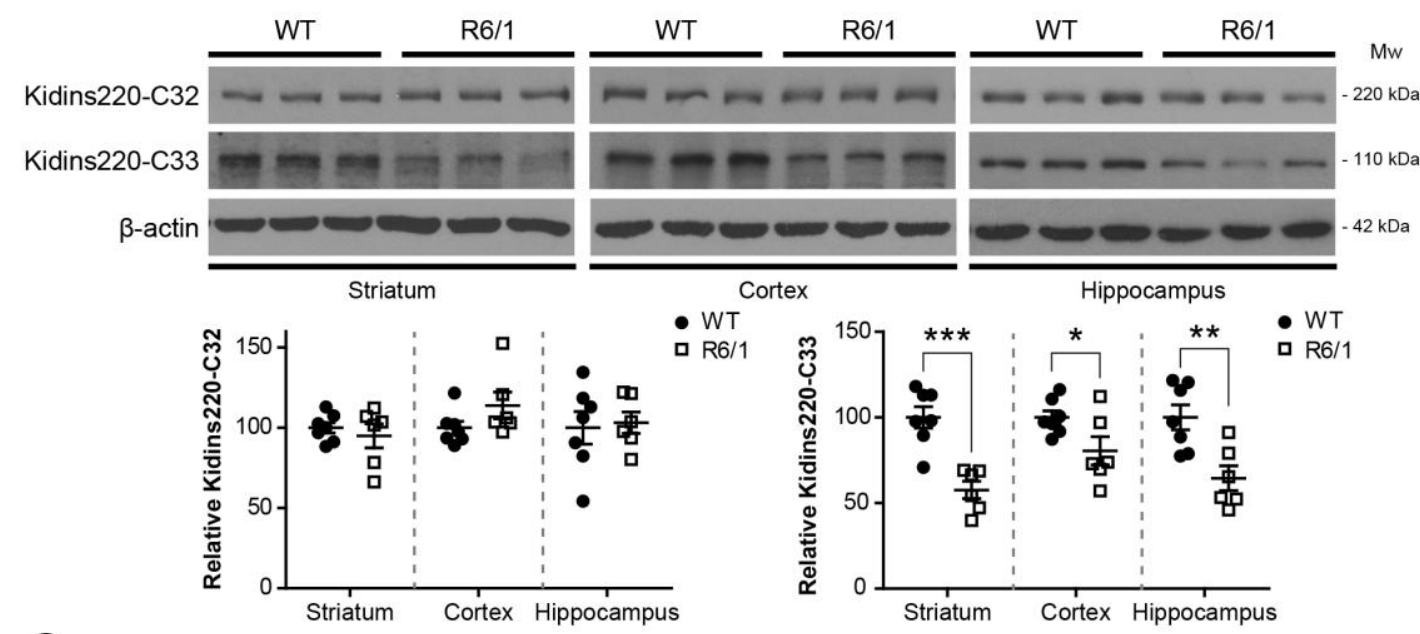

- WT 150 * * • WT

C
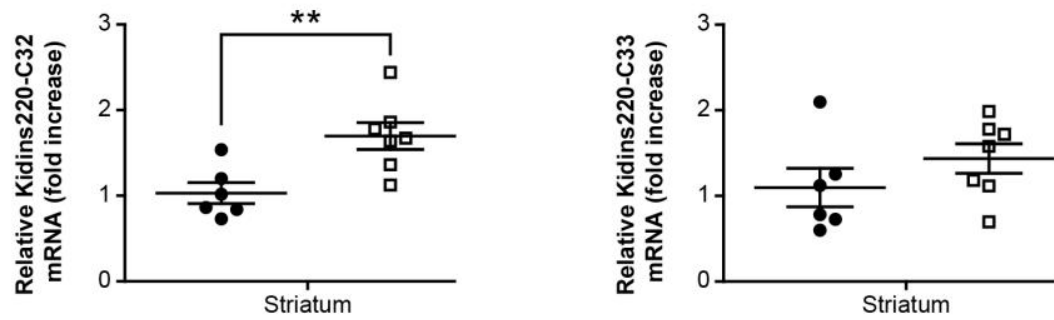

This article is protected by copyright. All rights reserved. 


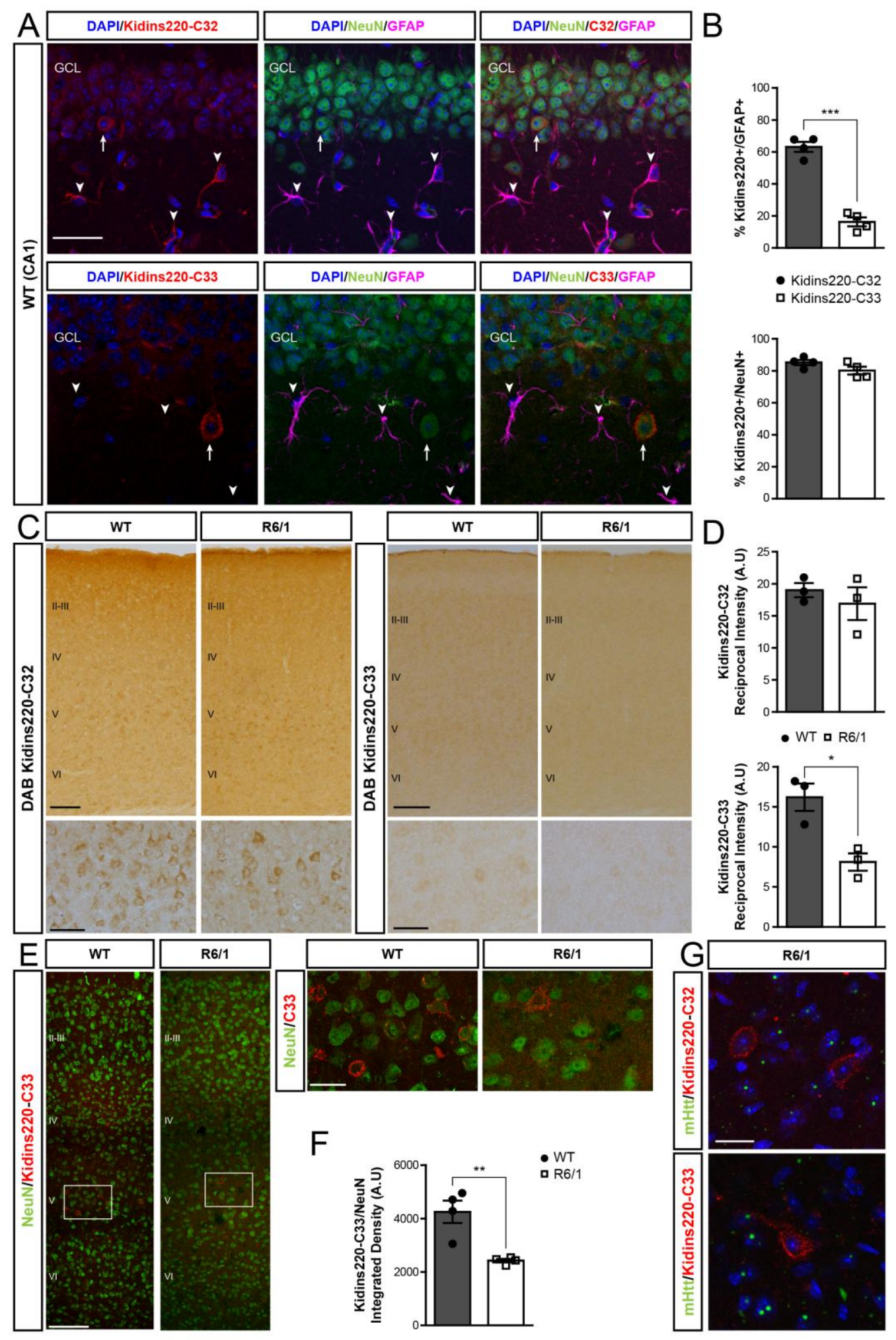

This article is protected by copyright. All rights reserved. 


\section{A}

Mouse GAA GAAAAT GCC GCC CCT GTG CTA GAT AGA CAG CGG TTC AGA AGA TCC AGT TTAAAC TGAG

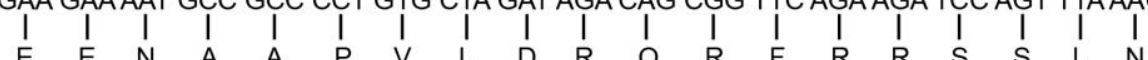

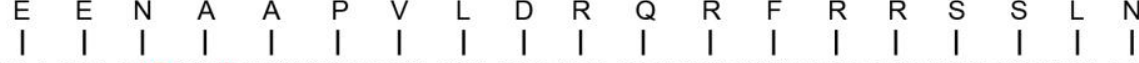

Rat GAA GAAAAC GCT GCC CCT GTG CTA GAT AGA CAG CGG TTC AGA AGA TCC AGT TTAAAC TGAG
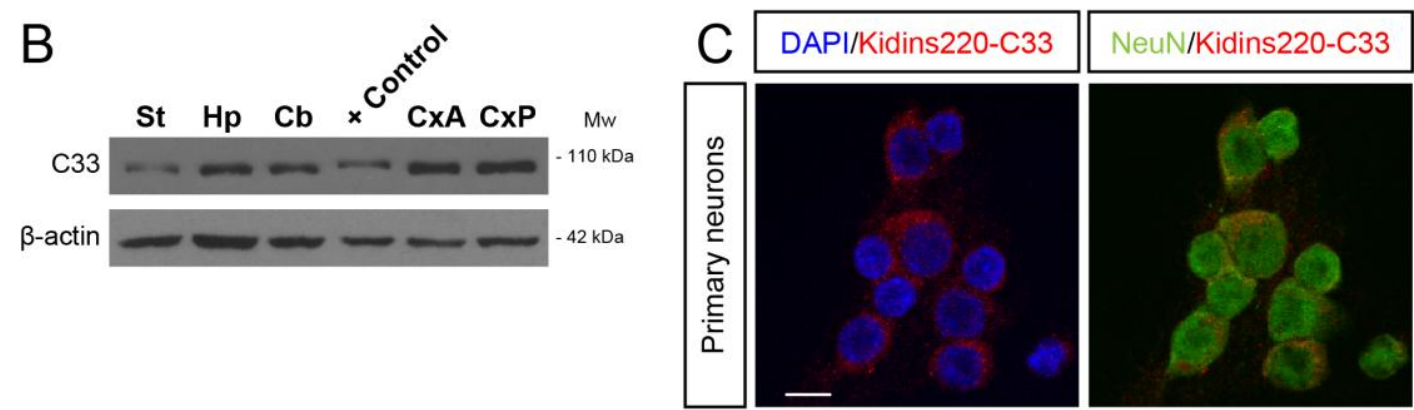

This article is protected by copyright. All rights reserved. 
A

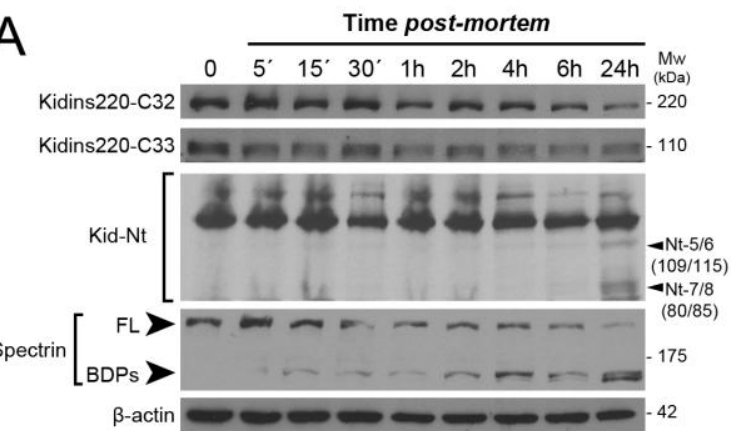

B
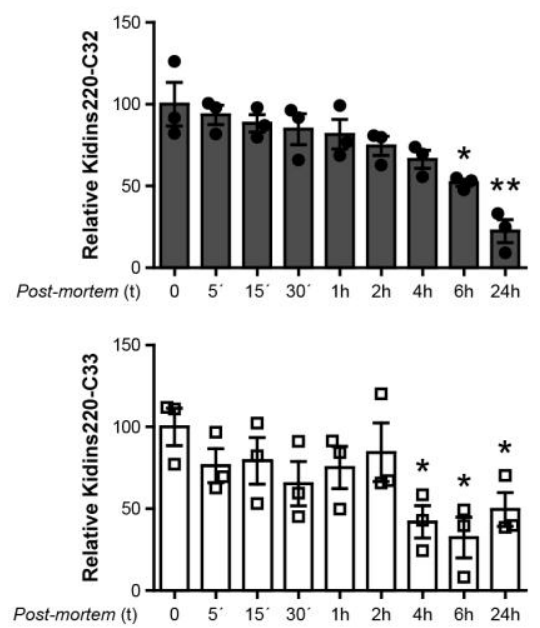

C
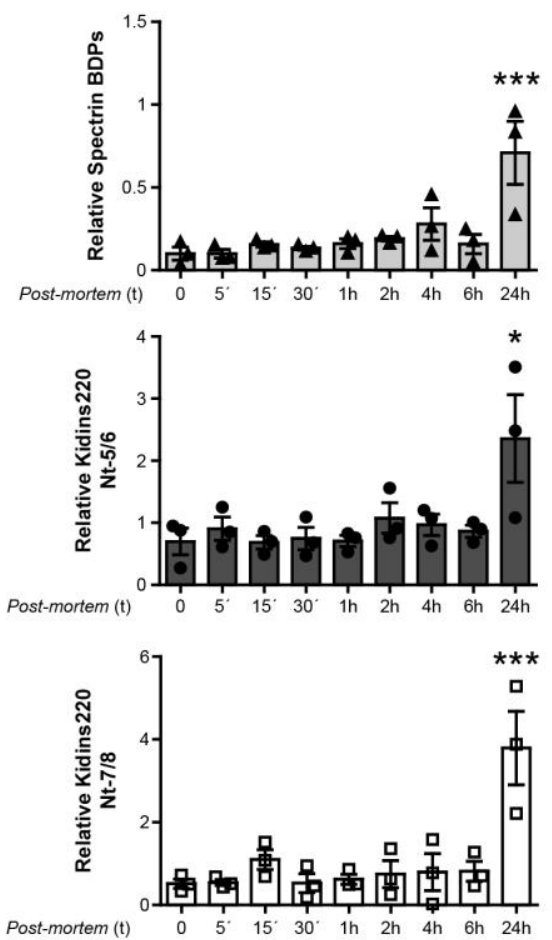

This article is protected by copyright. All rights reserved. 
A

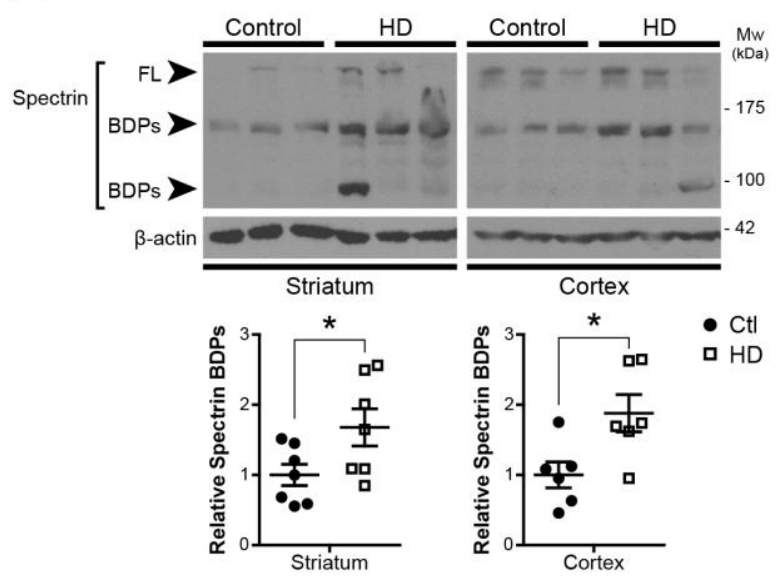

C

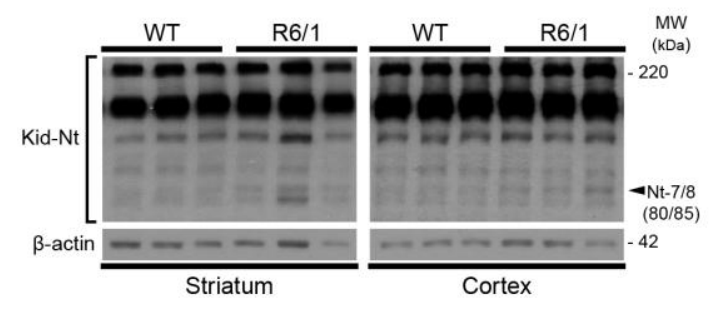

B
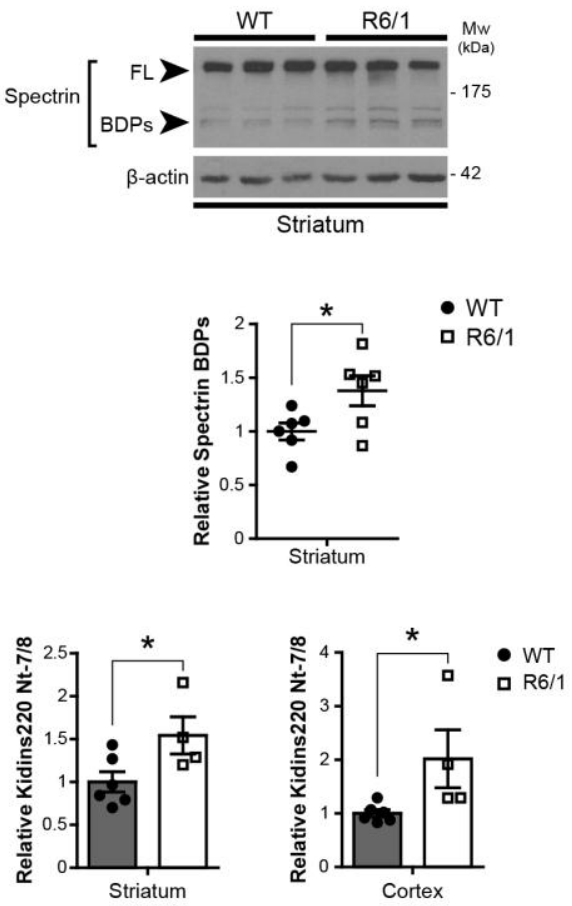
A
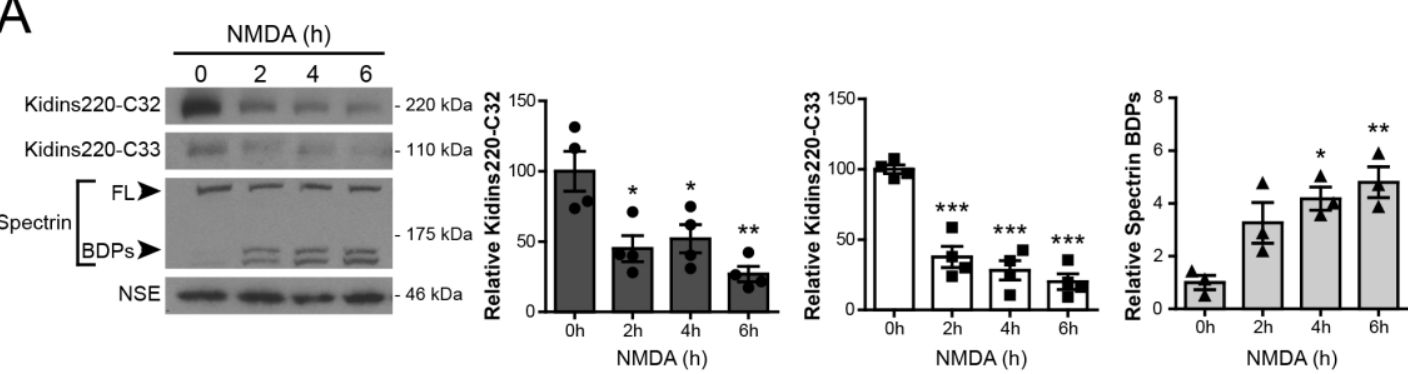

B

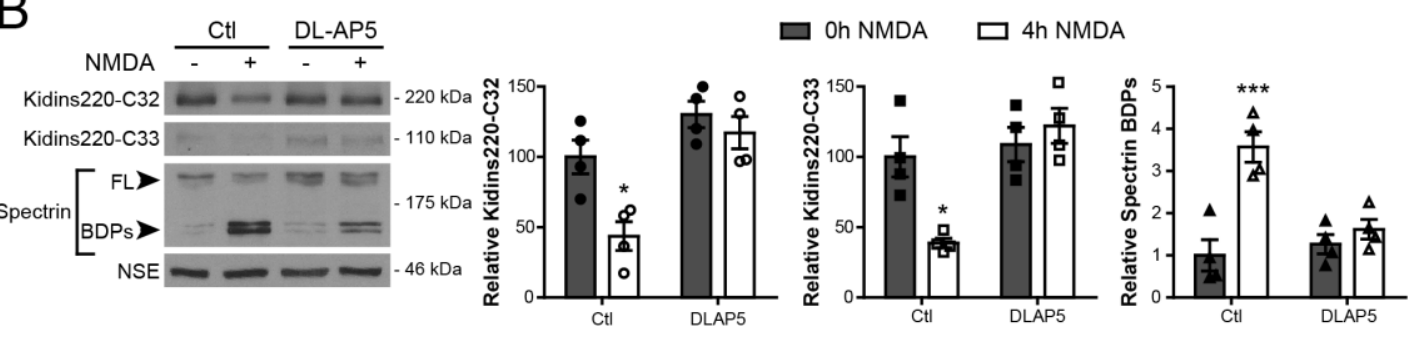

C
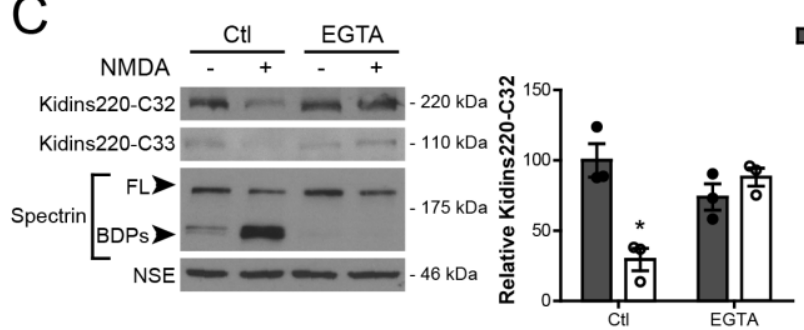

$\square$ Oh NMDA $\square$ 4h NMDA

D
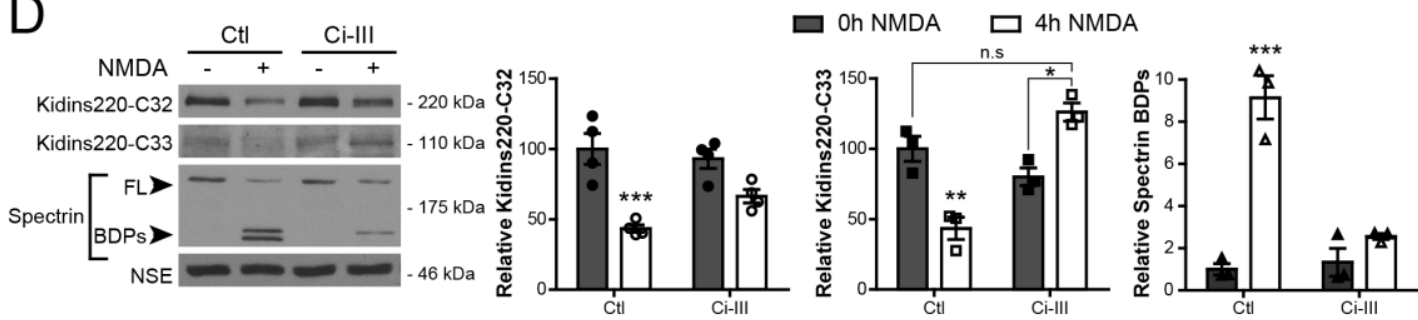

This article is protected by copyright. All rights reserved. 